UNIVERSIDADE DE SÃO PAULO

ESCOLA DE ENFERMAGEM

LUCIENE JACINTO DE SOUZA

CUIDADOS PALIATIVOS SOB A ÓTICA DAS ENFERMEIRAS DA ESTRATÉGIA DE SAÚDE DA FAMÍLIA

SÃO PAULO

2016 
LUCIENE JACINTO DE SOUZA

CUIDADOS PALIATIVOS SOB A ÓTICA DAS ENFERMEIRAS DA ESTRATÉGIA DE SAÚDE DA FAMÍLIA

Mestrado

EEUSP

2016 


\section{CUIDADOS PALIATIVOS SOB A ÓTICA DAS ENFERMEIRAS DA ESTRATÉGIA DE SAÚDE DA FAMÍLIA}

Dissertação apresentada ao Programa de Pós-graduação em Enfermagem (PPGE) Escola de Enfermagem da USP (EEUSP), da para obtenção do título de Mestre em Ciências.

Área de concentração: Cuidado em Saúde

Orientadora: $\operatorname{Prof}^{\mathrm{a}} \mathrm{Dr}^{\mathrm{a}}$ Maria Amélia de Campos Oliveira

\section{SÃO PAULO}


AUTORIZO A REPRODUÇÃO TOTAL OU PARCIAL DESTE TRABALHO, POR QUALQUER MEIO CONVENCIONAL OU ELETRÔNICO, PARA FINS DE ESTUDO E PESQUISA, DESDE QUE CITADA A FONTE.

Assinatura:

Data:

Catalogação na Publicação (CIP)

Biblioteca "Wanda de Aguiar Horta"

Escola de enfermagem da Universidade de São Paulo

Souza, Luciene Jacinto de Souza

Cuidados paliativos sob a ótica das enfermeiras da estratégia de saúde da família / Luciene Jacinto de Souza - São Paulo, 2016. 93p.

Dissertação de Mestrado - Escola de Enfermagem da Universidade de São Paulo.

Orientadora: $\operatorname{Prof}^{\mathrm{a}} \mathrm{Dr}^{\mathrm{a}}$ Maria Amélia de Campos Oliveira

1. Cuidados Paliativos. 2. Atenção Primária à Saúde. 3. Educação em Saúde. 
Nome: Luciene Jacinto de Souza

Título: Cuidados paliativos sob a ótica das enfermeiras da estratégia de saúde da família

Dissertação apresentada ao Programa de Pós-graduação em Enfermagem (PPGE) Escola de Enfermagem da USP (EEUSP), da para obtenção do título de Mestre em Ciências.

\section{Banca Examinadora}

Prof. Dr.

Instituição

Julgamento

Assinatura

Prof. Dr.

Instituição

Julgamento

Assinatura

Prof. Dr.

Instituição

Julgamento

Assinatura 


\section{Dedicatória}

À minha mãe, Dona Joana Muza de Souza que desde sempre me ensinou a estudar e gostar dos estudos. Com ela aprendi que a boa educação (em todos os sentidos) é a única coisa capaz de nos abrir portas. Sua dedicação inigualável me inspira hoje e sempre!!

Ao meu pai Valdecir Gabriel Jacinto de Souza, que me ensinou que "sempre é possível", basta querer verdadeiramente!!

Aos meus irmãos: Vladimir, Ana Lucia, Kátia e Alexandre, que sempre me apoiaram e se não fosse por eles, estar aqui não seria possível!!

À Minha prima Angélica Belém de Souza que me mostrou a direção de cada porta para os caminhos corretos da vida!!!

Ao meu grande amor, que depois de tanto tempo descobri único e verdadeiro, amigo, parceiro, personificação da gentileza, da atenção e do carinho humano; que me permitiu viver o melhor sentimento existente sobre a face da terra; experimentar os melhores momentos e as maiores surpresas da vida (e espero que seja assim até o último suspiro...); razão do meu afeto, amor que perdurou por mais de 20 anos, que faz meu coração bater forte todos os dias sustentando a vida apesar das agruras e obstáculos que dela fazem parte; amor que irá durar por toda a eternidade, assim como a alma: Edson Ghilardi, um ser ímpar, realmente único, que fez despertar nesse meu coração já um tanto quanto árido, o amor que é o único sentimento realmente capaz de transformar os seres humanos... Fez de mim, alguém melhor. A você toda a minha gratidão por me permitir descobrir a vontade de compartilhar bondade, gentileza e amor!!! 


\section{AGRADEÇO}

À queridíssima orientadora $\operatorname{Prof}^{\mathrm{a}} \operatorname{Dr}^{\mathrm{a}}$ Maria Amélia de Campos Oliveira, pelo carinho, atenção, empenho, amor à minha pessoa e ao trabalho árduo de orientação, que não desistiu de mim nem mesmo quando eu mesma quase desisti. Gratidão eterna por cada palavra de incentivo, pela persistência carinhosa e por permitir que nós chegássemos até aqui.

Às colegas Cintia, Jéssica e Vivian que com tanto empenho, amor e carinho ajudaram na condução desse estudo de diversas maneiras.

À Coordenadoria de Saúde da Região Oeste do município de São Paulo por seu empenho e apoio.

Aos amigos, familiares e alunos, que durante todo o processo foram capazes de compreender minha ausência e ainda conseguiram dar apoio e incentivo sempre!!!

Mas em primeiro lugar ao Grande Arquiteto do Universo, que tudo sabe, tudo vê e tudo faz acontecer e que me permitiu viver até aqui para trazer ao mundo através de minha experiência profissional, algo que acredito que será útil para a comunidade. 
"Eu me importo pelo fato de você ser você. Importo-me até o último momento de sua vida e faremos tudo o que está ao nosso alcance, não somente para ajudar você a morrer em paz, mas também para você viver bem até o dia da sua morte".

CICELY SAUNDERS

"Embora ninguém possa voltar atrás e fazer um novo começo, qualquer um pode começar agora e fazer um novo fim". 


\section{Resumo}

Introdução: $O$ interesse pelo tema investigado surgiu durante o curso de Graduação em Enfermagem, ao vivenciar junto aos colegas graduandos situações de morte e morrer. Em uma dada ocasião, já atuando como profissional, fui questionada por um membro da equipe de enfermagem sobre a real necessidade da manutenção de alguns procedimentos como, curativos e exames laboratoriais, para pacientes em cuidados paliativos, em fase final de vida. Impulsionada pelos acontecimentos descritos anteriormente e pela vontade de aprofundar meus conhecimentos sobre cuidados paliativos e compreender um pouco mais sobre aspectos relacionados a esse tema na enfermagem, ingressei no Programa de Pós- Graduação em Enfermagem da Escola de Enfermagem da Universidade de São Paulo. Objetivos: Revelar as concepções sobre Cuidados Paliativos (CP) das enfermeiras da Estratégia Saúde da Família (ESF), Caracterizar perfil sociodemográfico das enfermeiras da ESF, Identificar os significados atribuídos pelas enfermeiras da ESF aos CP, Conhecer as percepções dos enfermeiros sobre as necessidades de CP, Revelar as percepções das enfermeiras sobre a formação necessária para a prestação de CP na ESF. Método: Estudo descritivo, de caráter exploratório, com abordagem qualitativa. Resultados: Participaram do estudo doze enfermeiros, dos quais onze eram do sexo feminino, com idades entre 27 e 64 anos, com no mínimo 02 meses e no máximo 42 anos de formação em Enfermagem, com no mínimo uma e no máximo seis pós-graduações Lato Sensu. As mais citadas foram: Estratégia Saúde da Família, Saúde Pública e Administração Hospitalar. Para responder aos objetivos, realizamos o 
agrupamento dos dados de acordo com as semelhanças observadas nas respostas dos entrevistados para posterior formulação de temas e obtivemos como tais: Concepções sobre Cuidados Paliativos, Necessidades do paciente em Cuidados Paliativos e Formação do enfermeiro em CP. Conclusão: Os CP vieram para ocupar uma lacuna importantíssima, que precisava ser preenchida com certa urgência, proporcionando assim um cuidado mais efetivo para o paciente portador de doenças sem possibilidade de cura. Cuidado esse primordial para aplacar o sofrimento que nascia da falta de dignidade e impotência de pacientes e famílias diante de tamanha fúria e agressividade observadas muitas vezes por esses grupos; não por falta de empenho da equipe, mas sim em alguns casos, por falta de preparo efetivo para lidar com essas situações. Sendo assim, verificou-se a necessidade da capacitação e orientação para manusear e utilizar instrumentos que direcionem a prática da enfermeira da $A B$ que lida com paciente em CP e também do aprimoramento técnico científico direcionado especificamente para esse aspecto do processo de morte e morrer, pois, nesse momento tão delicado da vida do paciente e de seus familiares a equipe precisa estar preparada para acolher e desenvolver o melhor atendimento em saúde possível, pautado no conhecimento e também no cuidado humanizado. São Camilo de Lelis é autor da frase: "Mais coração nas mãos", ou seja, humanização e aprimoramento para tratar daquele que precisa de auxílio.

Descritores: 1. Cuidados Paliativos. 2. Atenção Primária à Saúde. 3. Educação em Saúde. 


\section{Abstract}

Introduction: The interest in the research theme emerged during the course of undergraduate nursing, to live together with fellow undergrads situations of death and dying. On a given occasion, already working as a professional, I was questioned by a member of the nursing staff on the real need to maintain some procedures as dressings and laboratory tests for patients in palliative care, end of life phase. Driven by the above-described events and the desire to deepen my knowledge about palliative care and understand a little more about aspects related to this topic in nursing, I joined the Graduate Program in Nursing at the University of São Paulo School of Nursing. Objectives: Develop the concepts of Palliative Care (PC) of the nurses of the Family Health Strategy (FHS), characterize sociodemographic profile of the FHS nurses identify the meanings attributed by the nurses of the ESF to the CP, know the perceptions of nurses about the needs of $\mathrm{CP}$, reveal the perceptions of nurses about the training required for the provision of $\mathrm{CP}$ in the FHS. Method: A descriptive study, exploratory, with qualitative approach. Results: The study included twelve nurses, eleven of whom were female, aged between 27 and 64 years with at least 02 months and no more than 42 years of training in nursing, with at least one and at most six postgraduates Lato sensu. The most cited were: the Family Health Strategy, Public Health and Hospital Administration. To meet the goals, perform the grouping of data according to the similarities observed in the respondents' answers to subsequent formulation of themes and obtained as such: Conceptions about palliative care, patient needs in palliative care and nursing training in CP. Conclusion: CP came to occupy a very important gap 
that needed to be filled with some urgency, thus providing a more effective care for patients with multiple diseases without possibility of cure. Watch this vital to assuage the suffering born of unworthiness and helplessness of patients and families faced with such fury and aggression observed many times by these groups; not for lack of team commitment, but in some cases, lack of effective preparation to deal with these situations. Thus, there was the need for training and guidance to handle and use tools that address the practice of $A B$ nurse who deals with patients in $\mathrm{CP}$ and also the scientific technical improvement specifically directed to that aspect of the process of death and dying as at that time so gentle the life of patients and their families the team must be prepared to accept and develop the best possible care in health, based on knowledge and also in humanized care. St. Camillus de Lellis is the author of the phrase: "More heart in hands", ie, humanization and improvement to treat one who needs help.

Keywords: 1. Palliative Care. 2. Primary Health Care. 3. Health Education. 


\section{LISTA DE SIGLAS}

AB - Atenção Básica

ABCP - Associação Brasileira de Cuidados Paliativos

ANCP - Academia Nacional de Cuidados Paliativos

APCP - Associação Portuguesa de Cuidados Paliativos

APS - Atenção Primária à Saúde

AVC - Acidente Vascular Cerebral

CA - Câncer

CEP - Conselho de Ética em Pesquisa

COFEN - Conselho Federal de Enfermagem

CP - Cuidados Paliativos

CPS - Clinical Prediction of Survival

CREMESP - Conselho Regional de Medicina de São Paulo

DAB - Departamento de Saúde Básica

DANT - Doenças e Agravos Não Transmissíveis

DPOC - Doença Pulmonar Obstrutiva Crônica

ECOG - Eastern Cooperative Oncology Group 
EEUSP - Escola de Enfermagem da Universidade de São Paulo

EMAD - Equipe Multiprofissional de Atenção Domiciliar

ESF - Estratégia Saúde da Família

OMS - Organização Mundial de Saúde

PACS - Programa de Agentes Comunitários de Saúde

PAP Score - Palliative Prognostic Score

PPI - Palliative Prognostic Index

RAS - Rede de Atenção à Saúde

SMADS - Secretaria Municipal de Assistência e Desenvolvimento Social

SUS - Sistema Único de Saúde

TCE - Traumatismo Crânio Encefálico

TCLE - Termo de Consentimento Livre e Esclarecido

UBS - Unidade Básica de Saúde 


\section{LISTA DE FIGURAS}

Figura 1 - Mapa das subprefeituras do município de São Paulo. São Paulo 2015 42

Figura 2 - Mapa das Supervisões Técnicas de Saúde da Coordenadoria Regional Centro-oeste. São Paulo, 2015

Figura 3 - Estabelecimentos e serviços de saúde da rede municipal vinculados à Coordenadoria Regional de Saúde Centro-Oeste do Município de São Paulo, julho de 2015. 44

Figura 4 - Estabelecimentos e serviços de saúde da rede municipal, Coordenadoria Regional de Saúde Centro-Oeste, Município de São Paulo, julho de 2015 .. 


\section{SUMÁRIO}

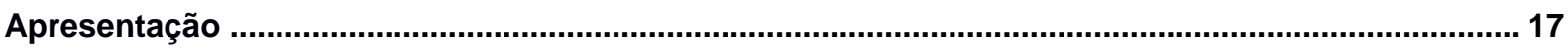

1. INTRODUÇAO

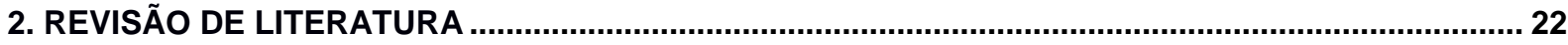

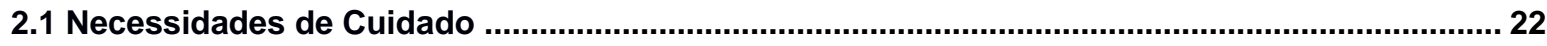

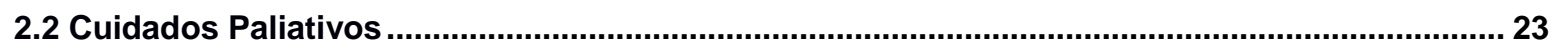

2.3 Cuidados Paliativos no Contexto Histórico ........................................................................... 28

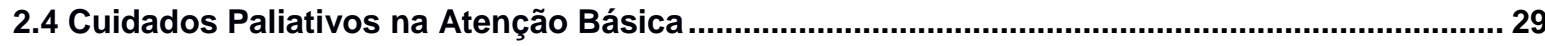

2.5 O Papel da Enfermeira na Atenção Básica e os Cuidados Paliativos .......................................... 34

3. OBJETIVO

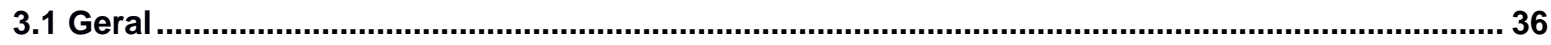

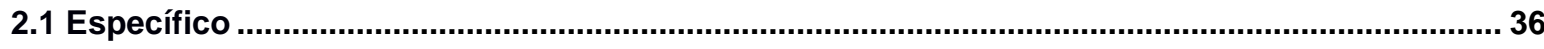

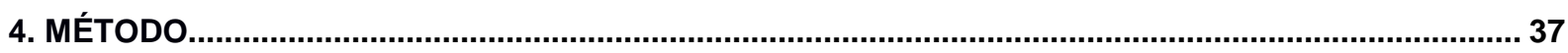

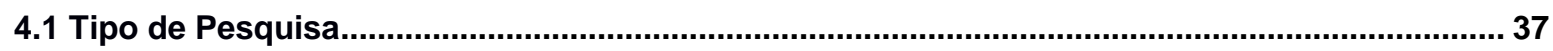

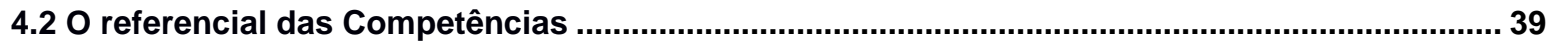

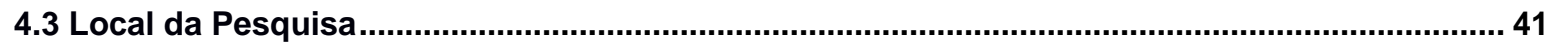

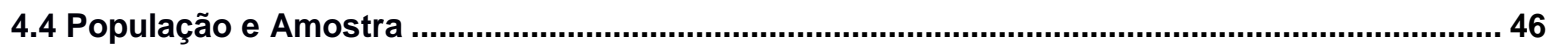

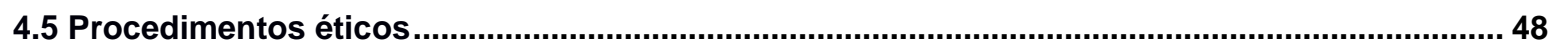

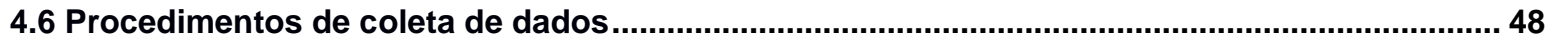

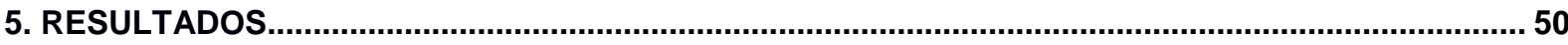

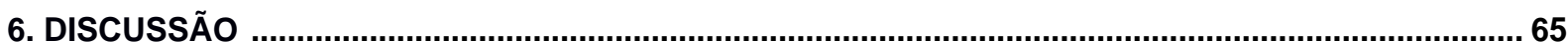

7. CONCLUSÃO

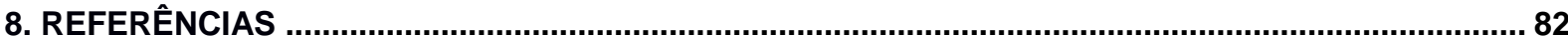

APÊNDICE A - Termo de consentimento livre e esclarecido ............................................................. 90

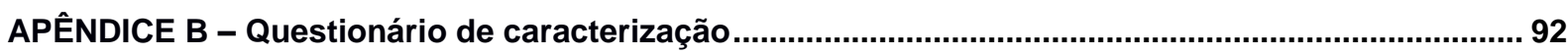

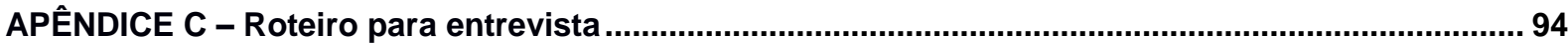




\section{APRESENTAÇÃO}

O interesse pelo tema investigado surgiu durante o curso de Graduação em Enfermagem, ao vivenciar junto aos colegas graduandos situações de morte e morrer. Tal fato instigou-me a refletir sobre como a experiência de assistir um paciente em final de vida poderia influenciar nossa formação acadêmica.

Tal reflexão culminou na execução do Trabalho de Conclusão de Curso (TCC), cujo principal objetivo foi medir e classificar o medo da morte manifestado pelos estudantes de enfermagem do primeiro e quarto anos. Os resultados desse estudo demonstraram que a maioria dos entrevistados apresentava algum tipo de medo da morte. Dos estudantes entrevistados, $68,7 \%$ possuíam algum curso relacionado à temática e já tinham acompanhado um indivíduo e/ou familiares no processo de morte e morrer. Quando questionados sobre como falariam sobre a morte com a família, 42,7\% relataram não possuírem formação acerca dos cuidados no final de vida. $A$ maioria dos estudantes referiram possuir algum tipo de medo relacionado a morte.

Ainda neste estudo, ao associar as variáveis, medo de morrer e medo de perder pessoas significativas observou-se que quanto maior o medo de morrer, maior é o medo de perder pessoas significativas. Um dado significante encontrado neste estudo associa o medo de morrer e o medo de perder pessoas significativas, indicando que, quanto maior o medo de morrer, maior o medo de perder pessoas significativas. 
Em minha experiência profissional como docente de um curso técnico em Enfermagem, supervisionando estágios na Atenção Básica e em uma unidade referenciada por uma instituição destinada a assistência ao paciente oncológico eu pude perceber a dificuldade dos alunos e profissionais de Enfermagem em lidar com algumas questões que envolvem o cuidado a indivíduos com doenças que ameaçam a continuidade da vida, dentre elas o processo de morte e morrer.

Alguns profissionais dessa Unidade de Saúde, motivados pela necessidade de discutirem sobre a abordagem aos pacientes em final de vida e seus familiares buscavam informações que pudessem os auxiliar no cuidado a ser prestado a essa população. Tais informações fornecidas por mim, também eram fonte de reflexão sobre a formação do profissional de saúde em relação aos cuidados em fase final de vida.

Em uma dada ocasião, ainda nessa Unidade de Saúde, fui questionada por um membro da equipe de enfermagem sobre a real necessidade da manutenção de alguns procedimentos como, curativos e exames laboratoriais, aos/para pacientes em cuidados paliativos, em fase final de vida. Frente a esta indagação passei a refletir sobre o conhecimento da equipe de enfermagem da Atenção Básica sobre Cuidados Paliativos.

Neste contexto, nota-se que alguns aspectos relacionados à formação dos profissionais de saúde em cuidados paliativos, a incorporação do conhecimento geral e específico sobre cuidados paliativos por parte desses 
profissionais à sua prática assistencial e as questões relacionadas ao cuidado no processo de morte e morrer merecem atenção.

Impulsionada pelos acontecimentos descritos anteriormente e pela vontade de aprofundar meus conhecimentos sobre cuidados paliativos e compreender um pouco mais sobre dados aspectos relacionados a esse tema na enfermagem, ingressei no Programa de Pós- Graduação em Enfermagem da Escola de Enfermagem da Universidade de São Paulo.

Durante os estudos no Programa de Pós-Graduação pude perceber que estamos avançando aqui no Brasil, mesmo que vagarosamente, porém ainda precisamos aumentar as possibilidades que o profissional enfermeiro tem de se preparar para lidar com o paciente em CP. 


\section{INTRODUÇÃO}

Este estudo busca revelar as concepções sobre cuidados paliativos (CP) na visão das enfermeiras da Atenção Básica $(A B)$, mais especificamente na Estratégia Saúde da Família (ESF) e buscará investigar quais conhecimentos, habilidades e atitudes são necessárias ao profissional enfermeiro para assistir pacientes em cuidados paliativos $(C P)$ na Atenção Básica $(A B)$, mais especificamente na Estratégia Saúde da Família. Partimos da hipótese de que, ao realizar visitas domiciliárias, tais enfermeiros podem se deparar com pacientes portadores de doenças que ameaçam a continuidade de vida desses, que uma vez atendidos no domicílio, nem sempre são identificados como elegíveis ou encaminhados para CP. E isso pode dificultar a identificação por parte do profissional enfermeiro da necessidade de prestar atendimento pautado em ações paliativas, controle de sintomas e outros tantos encaminhamentos específicos para o caso. Claro que sabemos que se tratam de profissionais generalistas, que recebem formação para tal e que para apresentar um olhar diferente, haveria a necessidade de haverem recebido alguma formação com base na filosofia dos CP e que isso não é comum. Porém, dentro de nossa hipótese contamos com a percepção por parte desse profissional da aparição da repetição dos sinais e sintomas característicos de desconforto causado pela presença de doenças ameaçadoras da continuidade da vida e dessa forma, do despertar de um olhar voltado às necessidades em saúde por parte desse paciente relativa à condição da impossibilidade de cura e de cuidados que visem melhor qualidade de vida nessas condições. 
A proposta do estudo foi responder a algumas questões, como por exemplo: qual o perfil do profissional enfermeiro que presta assistência a pacientes em $C P$ na $A B$ ? Quais conhecimentos, habilidades e atitudes são necessários a esse profissional (de acordo com a visão do mesmo), para a realização desses cuidados? Se os profissionais realizam a indicação de pacientes aos CP e de que maneira o fazem? Se esses enfermeiros utilizam instrumentos para caracterizar e indicar pacientes para CP e quais são esses instrumentos? Quais tipos de preparo recebem para lidar com esses pacientes?

A justificava para a realização desta pesquisa reside no fato de que apesar de termos no Brasil profissionais interessados, pesquisando e exercendo CP da melhor forma que conhecem, falta ainda no Brasil aprofundamento teórico e prático, que possibilitem uma melhor forma de identificação de pacientes que apresentam necessidades indicativas de atendimento em $\mathrm{CP}$ e isso, ainda hoje, faz com que os profissionais da área da saúde apresentem ainda muitas dúvidas quanto à filosofia dos $\mathrm{CP}$, quanto aos critérios de indicação, à conduta adotada e a pertinência de sua realização na AB. 


\section{REVISÃO DE LITERATURA}

\subsection{Necessidades de Cuidado}

No Brasil de antigamente (até a primeira metade do século XX), o perfil epidemiológico apresentava como doenças mais recorrentes as doenças transmissíveis. Porém, esse perfil aparece alterado a partir dos anos de 1960, quando a recorrência passa a ser das Doenças e Agravos Não Transmissíveis (DANT).

Podemos definir as DANT como o conjunto de agravos que não se baseiam em mecanismos de transmissão realizados por agentes etiológicos como as doenças transmissíveis, mas sim, na interação de vários fatores relacionados à natureza biológica, social, psicológica, etc.. Podemos citar como DANT, por exemplo, as doenças crônicas como as do aparelho circulatório, os transtornos mentais, a violência, os acidentes e os diversos tipos de cânceres.

Atualmente as DANT, correspondem a $70 \%$ dos gastos assistenciais com saúde no país (BRASIL, 2001).

Com a transformação do perfil epidemiológico e das possibilidades de assistência, os cuidados ao doente crônico que tem a continuidade de sua vida ameaçada, ou seja, os Cuidados Paliativos (CP) ganham importância na organização dos serviços e sistemas de saúde (BRASIL, 2011). 


\subsection{Cuidados Paliativos}

Cuidados Paliativos consistem na abordagem que promove qualidade de vida de pacientes e seus familiares diante de doenças que ameaçam a continuidade da vida, através da prevenção e alívio do sofrimento, o que requer a identificação precoce, avaliação e tratamento impecável da dor e outros problemas de natureza física, psicossocial e espiritual (OMS, 2002).

No último século, o perfil epidemiológico da população brasileira apresentou mudanças importantes. Na primeira metade do século $X X$, as doenças infecciosas transmissíveis eram as causas mais frequentes de morte. A partir dos anos 1960, os agravos não transmissíveis passaram a ocupar essa posição (Brasil, 2011). Tais mudanças demandam uma nova abordagem que permita realizar cuidados efetivos e de qualidade para atender as necessidades dos usuários dos serviços de saúde, inclusive os sem prognóstico de cura.

No Brasil, os CP ainda são relativamente recentes. Segundo os registros disponíveis, o Asilo da Penha pode ser considerado o primeiro hospice brasileiro. Surgiu em 1944 e teve importante papel na assistência aos pobres que morriam de câncer. (Floriani, 2010)

Na década de 1980 foram criadas outras unidades ou centros de CP no Brasil, a maior parte vinculada ao tratamento de pacientes com câncer ou a centros de tratamento de dor crônica, nos estados do Rio Grande do Sul, Santa Catarina, Paraná, São Paulo e Rio de Janeiro. (Floriani, 2010) 
Em 2000, o Hospital do Servidor Estadual de São Paulo criou seu Programa de CP que a princípio tratava apenas pacientes com câncer metastático. Em 2003 o Hospital abriu uma enfermaria de CP (Hermes, 2013).

Atualmente no Brasil os CP continuam mais diretamente ligados à área de oncologia. Os Centros de Alta Complexidade em Oncologia preveem a existência de equipes de CP, inclusive com suporte domiciliário e a instituição do Programa Nacional de Assistência à Dor e Cuidados Paliativos. Entretanto, outras moléstias tão incapacitantes ou devastadoras quanto o câncer não recebem a mesma atenção. (Florini, Schramm, 2007)

Em 2002, o Ministério da Saúde instituiu o Programa Nacional de Assistência à Dor e Cuidados Paliativos, por meio da Portaria GM/MS n¹9 de 03 de janeiro. Em 2005 foi fundada a Academia Nacional de Cuidados Paliativos, com objetivos semelhantes aos da Associação Brasileira de Cuidados Paliativos (ABCP) no que tange a divulgação, ensino e pesquisa, e empenhada no reconhecimento da medicina paliativa como especialidade médica. Porém, a realização desse objetivo não é tarefa fácil, devido à penetração reduzida da filosofia dos CP nos meios acadêmicos brasileiros, especialmente nas faculdades de medicina (Floriani, 2010).

Dados ABCP (2014) afirmam que há no Brasil 66 serviços de CP, 67\% dos quais concentrados na região Sudeste, $14 \%$ no Nordeste, $13 \%$ no Sul, 3\% no Norte e 3\% no Centro-oeste. No entanto, não há nenhuma equivalência entre eles e alguns podem ser questionados quanto a sua atividade ou atuação. 
É fundamental ampliar a formação sobre $\mathrm{CP}$, aprimorando o currículo dos cursos de graduação, com disciplinas que tratem da morte e dos cuidados, e promovendo a conscientização da população, que pouco discute a temática (Hermes, 2013).

É o exercício da arte do cuidar que, aliada ao conhecimento científico, proporciona o alívio do sofrimento relacionado à doença. Por ser parte fundamental da prática clínica, pode ocorrer de forma paralela às terapias destinadas à cura e ao prolongamento da vida (ANCP, 2012).

O CP não se baseia em protocolos, mas em princípios. Atualmente não se fala mais em terminalidade, mas em doenças que ameaçam a vida. Os CP estão indicados desde o diagnóstico, o que expande seu campo de atuação Tampouco se fala de impossibilidade de cura, mas da possibilidade ou não de tratamento modificador da doença, afastando dessa forma a ideia de que "não há mais nada a fazer". Essa abordagem inclui ainda a espiritualidade entre as dimensões do ser humano. Outro aspecto que merece destaque é que a família, que também deve ser lembrada e assistida durante todas as fases e também após a morte do paciente, no período de luto (ANCP, 2012).

Em 2002 a OMS estabeleceu os princípios gerais que embasam os CP:

$\checkmark$ Promovem o alívio da dor e de outros sintomas estressantes;

$\checkmark \quad$ Reafirmam a vida e veem a morte como um processo natural; 
$\checkmark \quad$ Não pretendem antecipar e nem postergar a morte;

$\checkmark \quad$ Integram aspectos psicossociais e espirituais ao cuidado;

$\checkmark \quad$ Oferecem um sistema de suporte que auxilie o paciente a viver tão ativamente quanto possível ate a sua morte;

$\checkmark \quad$ Auxiliam a família e os entes queridos a sentirem-se amparados durante todo o processo da doença;

$\checkmark \quad$ Devem ser iniciados o mais precocemente possível, junto a outras medidas de prolongamento devida como a quimioterapia, radioterapia, cirurgia, tratamento antirretroviral, drogas modificadoras do percurso da doença etc, e incluir todas as investigações necessárias para melhor compreensão e manejo dos sintomas (OMS, 2002).

Trata-se de filosofia de cuidado para as pessoas que enfrentam sofrimentos com o avançar de suas doenças crônicas e proximidade com a morte, comumente abandonadas no modelo assistencial preponderante em nosso país (Brasil, 2013, p.83).

Adoecer e morrer pode ocorrer de forma súbita, inesperada e violenta, mas também podem advir de forma lenta e gradativa, com diferentes formas e tempos para evoluir.

Em portadores de doenças crônico-degenerativas, síndromes demenciais e falências crônicas de sistemas (neuropatias, cardiopatias, pneumopatias, hepatopatias, vasculopatias etc.), o agravamento da doença pode ser lento. As práticas paliativas podem e devem ser aplicadas a todo e 
qualquer paciente com crônica, apenas variando o momento e a intensidade de cada procedimento. (Incontri, Santos, 2007).

Para cuidar com eficácia de pacientes em CP é preciso desenvolver tato, sensibilidade e aprimorar conhecimentos sobre a finitude. A Organização Mundial da Saúde (OMS) recomenda que sejam instituídos junto com outras medidas de prolongamento de vida, como quimioterapia, radioterapia, cirurgia, tratamento antirretroviral, drogas modificadoras do percurso da doença etc. Recomenda ainda que sejam feitas as investigações necessárias para melhor compreender as necessidades dos pacientes em CP, especialmente o manejo de sinais e sintomas (Brasil, 2013).

"A OMS em 2002, considerou que os cuidados paliativos podem e devem ser oferecidos o mais cedo possível no curso de qualquer doença crônica potencialmente fatal, definindo que os cuidados paliativos deveriam garantir uma abordagem que melhore a qualidade de vida de pacientes e suas famílias, na presença de problemas associados a doenças que ameaçam a vida, mediante prevenção e alívio de sofrimento pela detecção precoce e tratamento de dor ou outros problemas físicos, psicológicos, sociais e espirituais, estendendo-se inclusive à fase de luto". 


\subsection{Cuidados Paliativos no Contexto Histórico}

A palavra paliativo deriva do latim pallium, que designava o manto que cobria os peregrinos cristãos que cruzavam a Europa na Idade Média em busca de indulgências (Incontri, Santos, 2007). O CP também está associado historicamente ao termo hospice, usado para designar as hospedarias destinadas a receber e cuidar de peregrinos e viajantes (ANCP, 2012).

As primeiras casas para acolhimento de pobres e doentes foram fundadas no mundo bizantino, sob o reinado de Constantino, por influência de sua mãe, Santa Elena (Incontri, Santos, 2007). Na Europa, as instituições de caridade surgiram no século XVII como abrigos para órfãos, pobres e doentes, uma prática que se propagou por organizações católicas e protestantes em vários pontos do continente europeu. No século XIX, os hospices começaram a ter características de hospitais (CREMESP, 2008).

Foi em um hospice de Londres, o St. Lukes' Home, que a enfermeira e assistente social inglesa Cicely Saunders foi trabalhar em meados do século XX. Inconformada com o sofrimento humano, estudou medicina, formou-se aos 40 anos de idade e dedicou-se ao estudo do alívio da dor em doentes terminais (CREMESP, 2008). Em 1947, conheceu David Tasma, um judeu polonês com cerca de 40 anos, que morria de câncer no hospital, sem família e com poucos recursos. Trabalhando juntos, acabaram por se enamorar. O sonho de ambos foi criar um local onde enfermos pudessem estar como em suas casas, acompanhados pela família e cuidados por pessoas de múltiplas profissões, 
com atenção à dor e aos demais sintomas da fase terminal da vida. Estava desenhado o hospice moderno (Incontri, Santos, 2007).

Em 1967, Cecily Saunders fundou em Londres o St. Christhofer Hospice e deu início ao que hoje se denomina Movimento Hospice Moderno. A estrutura do St. Christhofer permitiu não apenas a assistência aos doentes, mas possibilitou o desenvolvimento do ensino e da pesquisa, recebendo bolsistas de vários países (Pessini, 2005). No início da década de 1970, o encontro de Cicely Saunders com a psiquiatra norte-americana Elizabeth Klüber-Ross, nos Estados Unidos, lá fez crescer o movimento hospice (CREMESP, 2008).

\subsection{Cuidados Paliativos na Atenção Básica}

A Constituição Federal de 1988 afirma que a saúde é um dever do Estado e um direito do cidadão. O cuidado em saúde é garantido à população brasileira pelo Sistema Único de Saúde (SUS). Criado pela Lei no 8.080, de 19 de setembro de 1990, também "Lei Orgânica da Saúde", o SUS é a tradução prática do princípio constitucional da saúde como direito de todos e dever do Estado.

A Constituição federal estabelece, no seu artigo $7^{\circ}$, que "as ações $e$ serviços públicos de saúde e os serviços privados contratados ou conveniados que integram o Sistema Único de Saúde (SUS) são desenvolvidos de acordo com as diretrizes previstas no art. 198 da Constituição Federal', obedecendo aos seguintes princípios: 
I - universalidade de acesso aos serviços de saúde em todos os níveis de assistência;

II - integralidade de assistência, entendida como conjunto articulado e contínuo das ações e serviços preventivos e curativos, individuais e coletivos, exigidos para cada caso em todos os níveis de complexidade do sistema;

III - preservação da autonomia das pessoas na defesa de sua integridade física e moral;

IV - igualdade da assistência à saúde, sem preconceitos ou privilégios de qualquer espécie;

V - direito à informação, às pessoas assistidas, sobre sua saúde;

VI - divulgação de informações quanto ao potencial dos serviços de saúde e a sua utilização pelo usuário;

VII - utilização da epidemiologia para o estabelecimento de prioridades, a alocação de recursos e a orientação programática;

VIII - participação da comunidade;

IX - descentralização político-administrativa, com direção única em cada esfera de governo: a) ênfase na descentralização dos serviços para os municípios; b) regionalização e hierarquização da rede de serviços de saúde;

X - integração em nível executivo das ações de saúde, meio ambiente e saneamento básico; 
XI - conjugação dos recursos financeiros, tecnológicos, materiais e humanos da União, dos Estados, do Distrito Federal e dos Municípios na prestação de serviços de assistência à saúde da população;

XII - capacidade de resolução dos serviços em todos os níveis de assistência e

XIII - organização dos serviços públicos de modo a evitar duplicidade de meios para fins idênticos (Brasil, 1990).

As diretrizes do SUS são o conjunto de recomendações técnicas e organizacionais voltadas para problemas específicos, produzidas pelo Ministério da Saúde, com o concurso de especialistas de reconhecido saber na área de atuação, de abrangência nacional. Orientam a configuração geral do sistema de saúde em todo o território nacional, respeitadas as especificidades de cada unidade federativa e de cada município (Brasil, 1990). Uma dessas diretrizes é a integralidade da assistência, entendida como "o conjunto articulado e contínuo das ações e serviços preventivos e curativos, individuais e coletivos, exigidos para cada caso em todos os níveis de complexidade do sistema" (Brasil, 2006a).

A Atenção Básica $(A B)$ é a principal porta de entrada para o SUS. Desenvolve um conjunto de ações de caráter individual e coletivo, situadas no primeiro nível de atenção do Sistema, voltadas para a promoção da saúde, a prevenção de agravos, tratamento e a reabilitação (Política Nacional de Atenção Básica - PNAB, Brasil, 2006b). Tem como princípios ordenadores a 
acessibilidade, a longitudinalidade, a integralidade, a responsabilização, a coordenação e a resolubilidade.

A $A B$ é a ordenadora do sistema locorregional, integrando os diferentes pontos que compõem a Rede de Atenção à Saúde - RAS (Brasil, 2006c). Na $\mathrm{AB}$, a assistência à saúde é desenvolvida por equipes multiprofissionais, com responsabilidade sanitária sobre as diferentes coletividades adstritas a territórios bem delimitados. A atuação dos profissionais da $A B$ deve considerar as características socioculturais dos grupos sob seus cuidados e a dinamicidade da vida social (Brasil, 2008). A Estratégia Saúde da Família (ESF) e o Programa de Agentes Comunitários de Saúde (PACS) preveem visitas ao domicílio realizadas por equipes multiprofissionais.

Mesmo desenvolvendo ações não consideradas específicas de $\mathrm{CP}$, a rede de serviços da $A B$, em conjunto com a ESF e o PACS, pode ser qualificada para incorporar algumas atribuições referentes a esse tipo de atendimento. Com isso os CP ganharão visibilidade e a devida relevância dentro desses serviços.

O CP está presente na $A B$ desde a sua definição, pois a ela cabe organizar atividades voltadas ao cuidado longitudinal das famílias. Um dos pontos nevrálgicos no acompanhamento dos pacientes com doenças avançadas e em fase terminal consiste em evitar a ruptura da continuidade dos cuidados a partir do momento em que não pode mais ser ofertado tratamento curativo (Florini, Schramm, 2007). 
Para o Departamento de Atenção Básica (DAB) da Secretaria de Atenção à Saúde, os CP devem ser prestados a partir do diagnóstico da doença com risco de morte, sendo adaptados às necessidades dos pacientes e seus familiares à medida que a doença progride. Incluem o respeito à vida, considerando a morte como processo natural, sem a intenção de apressá-la ou adiar, oferecendo apoio para que os pacientes possam viver bem, sem sofrimento físico, emocional e espiritual, até a sua morte (Brasil, 2013).

Recomenda-se que os CP sejam dispensados no domicílio sempre que possível. Com isso, a responsabilidade pelo cuidado aos doentes que estão morrendo recai sobre as famílias, que necessitam de apoio para enfrentar esse momento de transição. Assim, prestar cuidados a pacientes no fim da vida tornou-se uma competência necessária para os serviços da $A B$, principalmente pela proximidade que o cuidado na coletividade proporciona entre as equipes profissionais, os doentes e as famílias (Baliza et al, 2012).

Exercer $\mathrm{CP}$ no contexto da $\mathrm{AB}$ é bastante desafiador e muitas vezes os profissionais se deparam com a necessidade de tomar decisões éticas sobre a morte e o morrer. Entretanto, raramente são abordados no contexto da $A B$ como cuidados que apresentam certo grau de especificidade e muitas vezes acabam sendo rotulados de "cuidados básicos" (Silva et. al, 2013). Entretanto, os CP envolvem boa preparação, capacitação e autoconhecimento. Identificar as próprias limitações é primordial para entender que os destinatários do cuidado também possuem limitações e necessidades. O aprofundamento do estudo sobre as competências necessárias para lidar com esse processo pode 
colaborar para que o profissional de saúde compreenda que ter limitações pode não ser necessariamente um problema. O problema reside em não as reconhecer e deixar que interfiram negativamente na prática assistencial, tornando-a inadequada.

\subsection{O papel da enfermeira na atenção básica e os cuidados paliativos}

Diante da falta de preparo específico dos profissionais para exercer esse cuidado na $A B$, acredita-se ser importante conhecer sua experiência em relação ao desafio de cuidar de famílias que vivenciam a fase de final de vida de um de seus integrantes, já que nesse processo também está implícito o cuidado em um contexto de múltiplas perdas (Silva et.al 2013).

Compete à enfermeira da $\mathrm{AB} O$ atendimento ao paciente com doenças crônicas que ameacem a continuidade da vida, seja na própria unidade ou no domicílio. Cabe examinar seu posicionamento diante do complexo processo de envelhecimento, dos agravos advindos de doenças crônico-degenerativas e também das características vindas do processo de final da vida, para identificar as dificuldades que enfrenta para prestar tais cuidados. Como a enfermeira se prepara para lidar com esses processos? Existem habilidades específicas que essa profissional necessita para realizar CP?

O conhecimento dos significados atribuídos pelas enfermeiras aos CP e de suas experiências de cuidado permite definir conceitos, fortalecer teorias e aperfeiçoar estratégias, ajudando-as a intervir efetivamente, respeitando a 
subjetividade das famílias diante das situações de cuidado, perda e luto. (Bousso et. al, 2009). 


\section{OBJETIVO}

\subsection{Geral}

$\checkmark$ Revelar as concepções sobre Cuidados Paliativos (CP) das enfermeiras da Estratégia Saúde da Família (ESF).

\subsection{Específicos}

$\checkmark$ Caracterizar perfil sociodemográfico das enfermeiras da ESF

$\checkmark$ Identificar os significados atribuídos pelas enfermeiras da ESF aos CP

$\checkmark$ Conhecer as percepções dos enfermeiros sobre as necessidades de CP

$\checkmark$ Revelar as percepções das enfermeiras sobre a formação necessária para a prestação de CP na ESF 


\section{MÉTODO}

\section{1. $\quad$ Tipo de Pesquisa}

Estudo descritivo, de caráter exploratório, com abordagem qualitativa. A pesquisa exploratória é o primeiro passo de todo o trabalho científico e tem como finalidades proporcionar mais informações sobre determinado assunto, facilitar a delimitação de um tema de trabalho, definir os objetivos ou formular as hipóteses de uma pesquisa posterior ou descobrir novo tipo de enfoque para trabalho que se tem em mente. (Andrade, 2003)

Tais pesquisas visam proporcionar maior familiaridade com o problema, com vistas a torná-lo mais explícito ou a constituir hipóteses. Buscam o aprimoramento de ideias sobre o tema ou a descoberta de intuições (insights). Seu planejamento é, portanto, bastante flexíveis, de modo a possibilitar a consideração dos mais variados aspectos relativos ao fato estudado (Gil, 2007).

Assim como a pesquisa descritiva, a investigação exploratória começa com um fenômeno de interesse. No entanto, em vez de simplesmente observar e descrever esse fenômeno, os pesquisadores investigam sua natureza, o modo como se manifesta e as condições a ele relacionadas (Polit, 2011). Realizam-se estudos exploratórios quando o objetivo é examinar um tema ou problema de pesquisa pouco estudado, do qual se tem muitas dúvidas ou não foi abordado antes (Sampieri, 2006). 
Pensa-se que a realização de um estudo exploratório, por ser aparentemente mais simples, elimina o tratamento científico cuidadoso que todo investigador tem presente nos trabalhos de pesquisa. Entretanto, esse tipo de investigação não prescinde de revisão da literatura, entrevistas, emprego de questionários etc., dentro de um esquema elaborado com a severidade característica de um trabalho científico (Triviños, 1987).

Os estudos exploratórios servem para familiarizar o pesquisador com fenômenos relativamente desconhecidos, para obter informações sobre a possibilidade de realizar uma pesquisa mais completa sobre um contexto particular (Sampieri, 2006). Permitem ao investigador aumentar sua experiência em torno de determinado problema, ao partir de uma hipótese, e aprofundar seus estudos nos limites de uma realidade específica, buscando seus antecedentes, a fim de obter maior conhecimento para em seguida planejar uma pesquisa descritiva ou de tipo experimental (Triviños, 1987).

Existem pesquisas que buscam contribuir para a solução de um determinado problema e outras que têm como objetivo principal testar uma teoria ou relatar evidências empíricas em favor dela. Também existem estudos que, como resultado final, pretendem gerar uma formulação do problema ou induzir o conhecimento. (Sampieri, 2006)

Os estudos descritivos pretendem medir ou coletar informações de maneira independente ou conjunta sobre os conceitos ou variáveis a que se referem. Buscam especificar propriedades e características importantes do fenômeno em análise (Sampieri, 2006). Medem, avaliam ou coletam dados 
sobre diversos aspectos, dimensões ou componentes do fenômeno, objeto do estudo. Do ponto de vista científico, descrever é coletar dados (para os pesquisadores quantitativos, medir; para os qualitativos, coletar informações). Isto é, em um estudo descritivo seleciona-se uma série de questões e mede-se ou coleta-se informação sobre cada uma delas, para assim (vale a redundância) descrever o que se pesquisa (Sampieri, 2006).

\subsection{0 referencial das competências}

Por que falar de competências nesse estudo, se os objetivos são revelar as concepções sobre Cuidados Paliativos (CP) das enfermeiras da Estratégia Saúde da Família (ESF), identificando os conhecimentos, habilidades e atitudes necessárias às enfermeiras para realizar $C P$ na $A B$ ?

Justamente para tentar responder a essa questão, uma vez que partiremos do pressuposto de que competências são na verdade, em sua forma básica, o conjunto formado de conhecimentos, habilidades, atitudes, interesses, traços, valor ou outra característica pessoal; são aquelas características pessoais essenciais para o desempenho da atividade e que diferenciam o desempenho das pessoas (Chiavenato, 2002).

O conceito de competência profissional surgiu nos anos 60 nos Estados Unidos e a formação e qualificação baseada em competências difundiram-se nos Estados Unidos e na Inglaterra nos anos 80. Um elemento central na competência é o desempenho efetivo, definido como a forma de alcançar resultados específicos com ações também específicas. (Marques \& Egry, 2011). 
Para Perrenoud (1999), os significados de competência são múltiplos. O autor define como sendo uma capacidade de agir eficazmente em um determinado tipo de situação, apoiada em conhecimentos, mas limitar-se a eles. Quase toda ação mobiliza alguns conhecimentos, algumas vezes elementares e esparsos, outras vezes complexos e organizados em rede (Perrenoud, 2000).

Cada elemento de um referencial de competências pode remeter a práticas antes seletivas e conservadoras ou a práticas democratizantes e renovadoras (Perrenoud, 2000).

Le Boterf (2000) define competência como a mobilização de recursos, isto é, saber gerir, gerenciar. Perrenoud (2001) define-as como o conjunto formado por conhecimentos, savoir-afaire e posturas, e também ações e as atitudes necessárias ao exercício da profissão.

Quando se trata de competências profissionais, Perrenoud (2002) considera que ser competente é ser tolerante, buscando continuamente 0 aperfeiçoamento da prática, sua correção, retomada para, com modéstia, ver os diferentes aspectos que devem ser considerados em função de um contexto, da história. Tomar uma decisão envolve conflitos e oposições e frequentemente os profissionais podem se sentir pouco autorizados ou pouco competentes para tomar decisões a respeito do próprio trabalho.

Macedo (2000) afirma que ser competente é ousar julgar em momentos de incerteza, dificuldade, ambivalência, contradição, dúvida, e por isso, ser 
competente é ser tolerante e generoso. Outras características da competência são saber agir, saber dizer, saber comunicar, saber fazer, saber explicar, saber compreender, saber encontrar a razão, ou seja, a competência é aquilo que organiza e dá base para que algo possa se realizar enquanto representação, pensamento, ação, compreensão ou sentido (Le Boterf, 2000).

Por isso, no desenvolvimento de competências, estes verbos são fundamentais: abstrair, ou seja, retirar de uma situação algo que tenha valor de lição; generalizar, transferir com as adaptações que sempre serão necessárias; aprender com a experiência, sabendo que a experiência sempre será suficiente porque a situação é cada vez única e original, embora seja possível recorrer a ela, mobilizá-la (Perrenoud, 2002).

\subsection{Local de Pesquisa}

O estudo foi desenvolvido em unidades da ESF da Coordenadoria de Saúde da Região Oeste do município de São Paulo, na subprefeitura da Lapa, administradas por meio da parceira da Prefeitura com a Organização Social Fundação Faculdade de Medicina.

Para alcançar os objetivos do estudo foi necessário eleger uma região que apresentasse um número expressivo de pacientes em CP. Para isso foi utilizado o estudo desenvolvido em 2013 no município de São Paulo por Cássia Regina de Paula Paz, intitulado Cuidados paliativos na atenção primária à saúde: novos desafios em 2013. Nele a pesquisadora utilizou a lista de pacientes atendidos pelo Programa de Dispensação de Insumos para 
Pacientes com Incontinência da Secretaria de Saúde do Município para determinar o local com maior número de pacientes em CP.

Assim, optou-se pela região oeste da cidade de São Paulo, que possui uma área de 1.461 km2 e uma população estimada em 2010 de 11.253 .503 habitantes. Está dividida em 31 subprefeituras (Figura 1).

Figura 1 - Mapa das subprefeituras do município de São Paulo. São Paulo 2015.

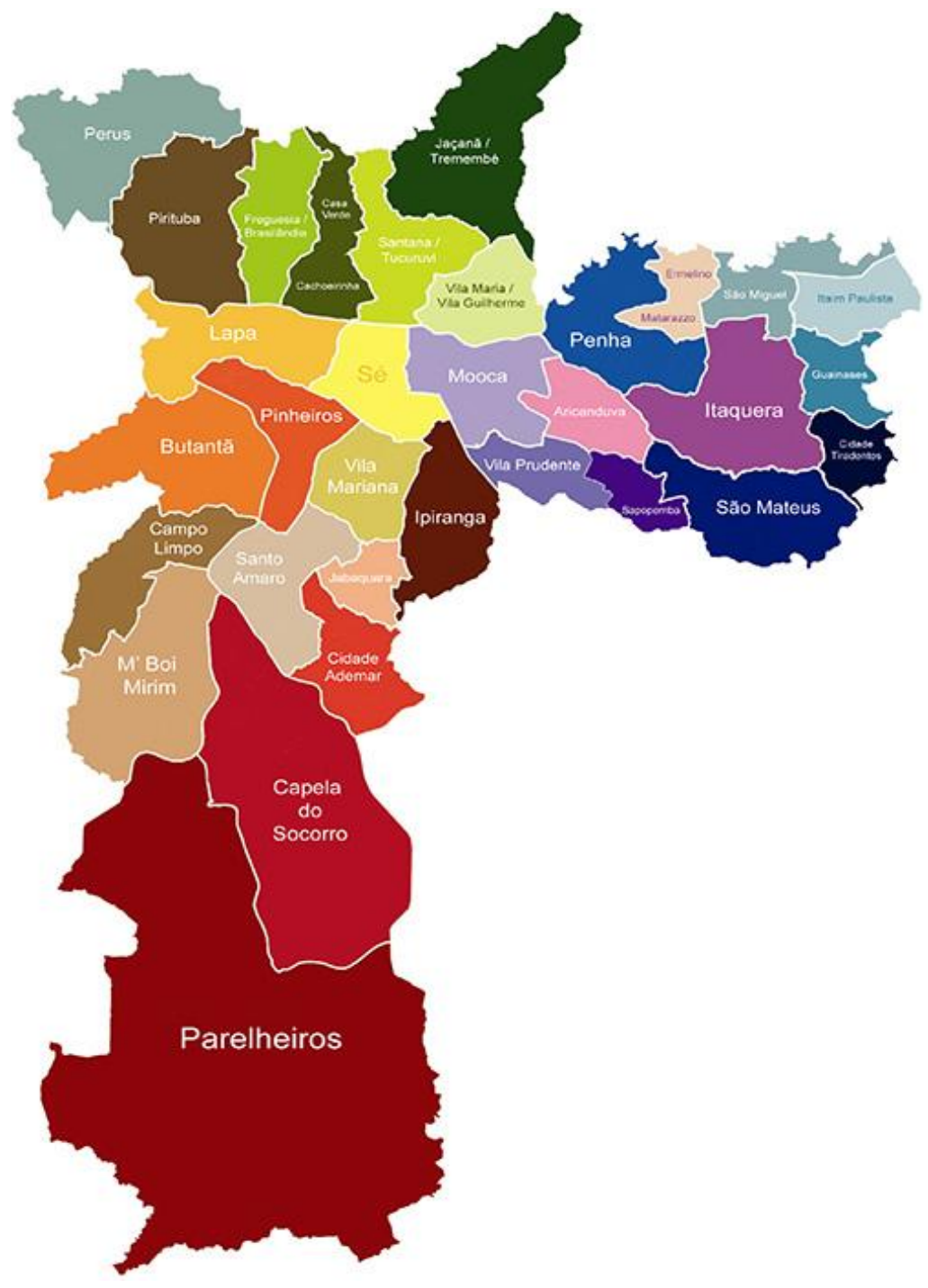

Fonte: Prefeitura de São Paulo. Disponível em:

http://www.prefeitura.sp.gov.br/cidade/secretarias/subprefeituras/subprefeituras/mapa/index.php?p=14894 
A Secretaria Municipal de Saúde de São Paulo conta com seis coordenadorias regionais: (Norte, Sul, Leste, Sudeste, Oeste e Centro) e 25 Supervisões Técnicas (Figura 2).

Figura 2 - Mapa das Supervisões Técnicas de Saúde da Coordenadoria Regional Centro-oeste. São Paulo, 2015.

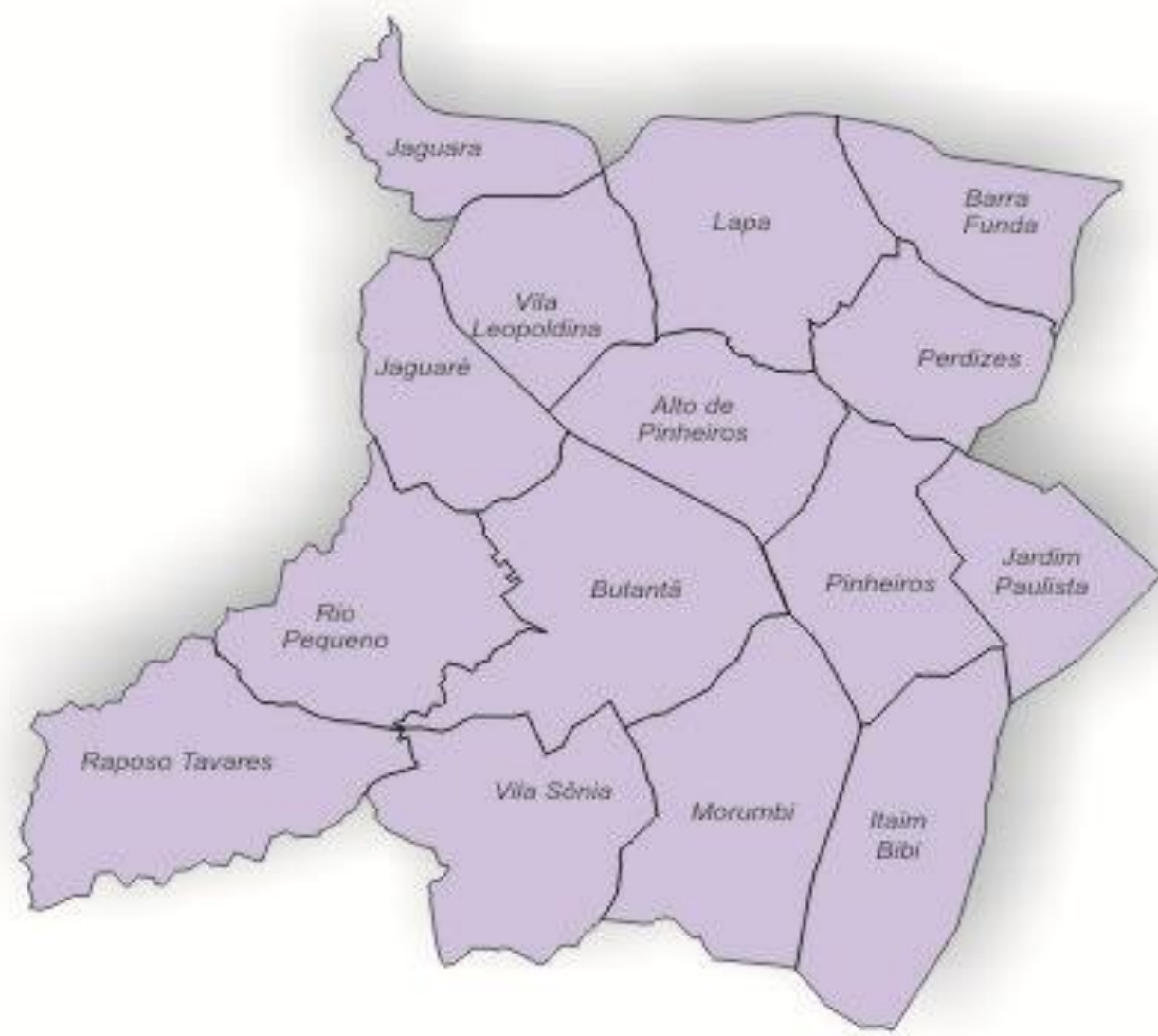

Fonte: Prefeitura de São Paulo. Disponível em:

http://www.prefeitura.sp.gov.br/cidade/secretarias/saude/organizacao/index.php? $p=5406 \#$ este

A subprefeitura da Lapa corresponde a uma área de $40,10 \mathrm{~km}^{2} \mathrm{da}$ cidade de São Paulo, com uma população estimada de 305.526 habitantes em 2010. É composta pelos distritos de Barra Funda, Jaguara, Jaguaré, Lapa, Perdizes e Vila Leopoldina. Em 2014, contava com 26 estabelecimentos de saúde, dos quais nove eram Unidades Básicas de Saúde (UBS). 
Já a subprefeitura de Pinheiros corresponde a uma área de $31,70 \mathrm{~km}^{2}$, com uma população estimada de 289.743 pessoas em 2010. É composta pelos distritos de Alto de Pinheiros, Itaim Bibi, Jardim Paulista e Pinheiros. Em 2013, contava com 11 estabelecimentos de saúde, dos quais seis eram UBS.

Figura 3 - Estabelecimentos e serviços de saúde da rede municipal vinculados à Coordenadoria Regional de Saúde Centro-Oeste do Município de São Paulo, julho de 2015.
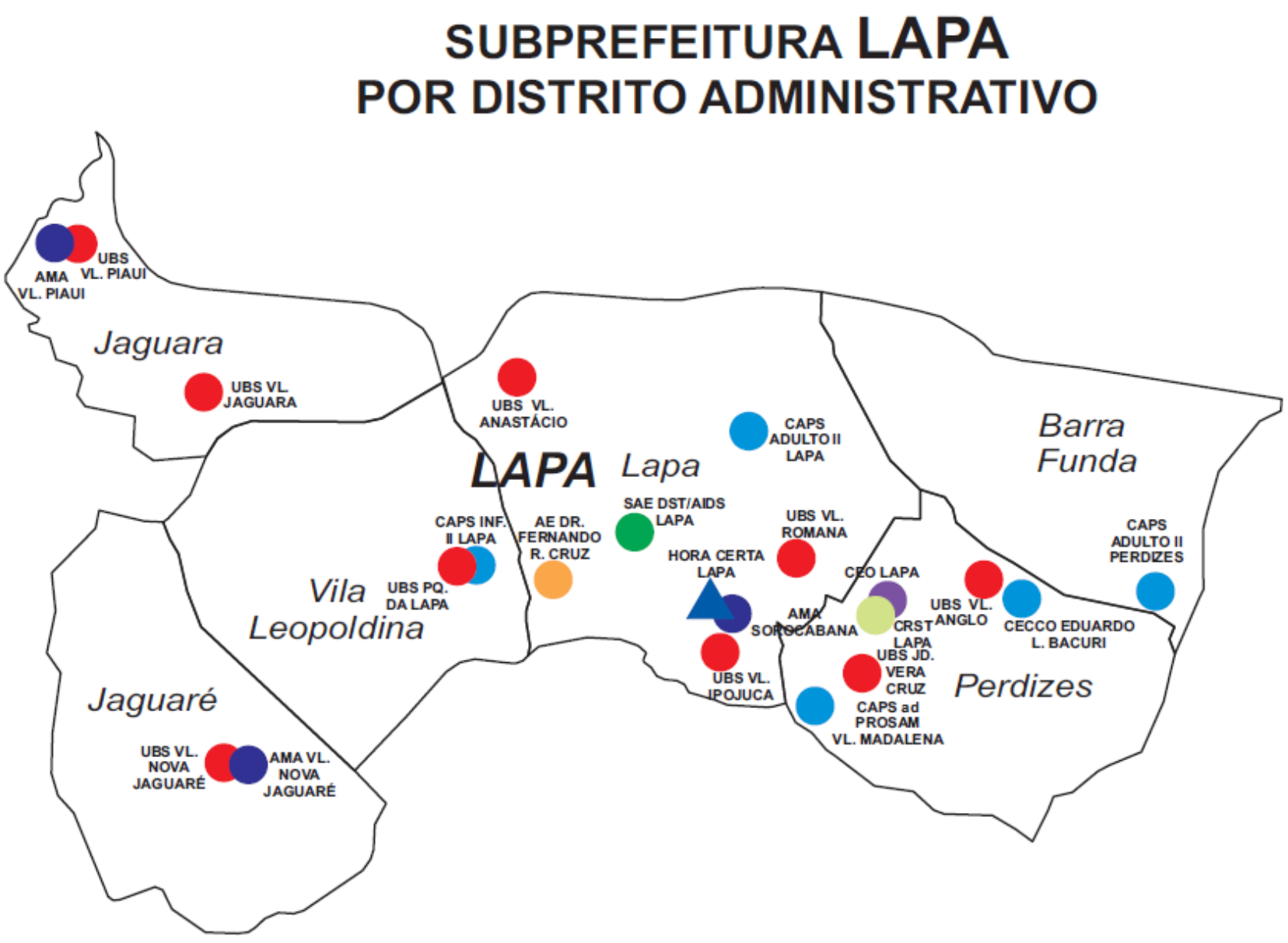


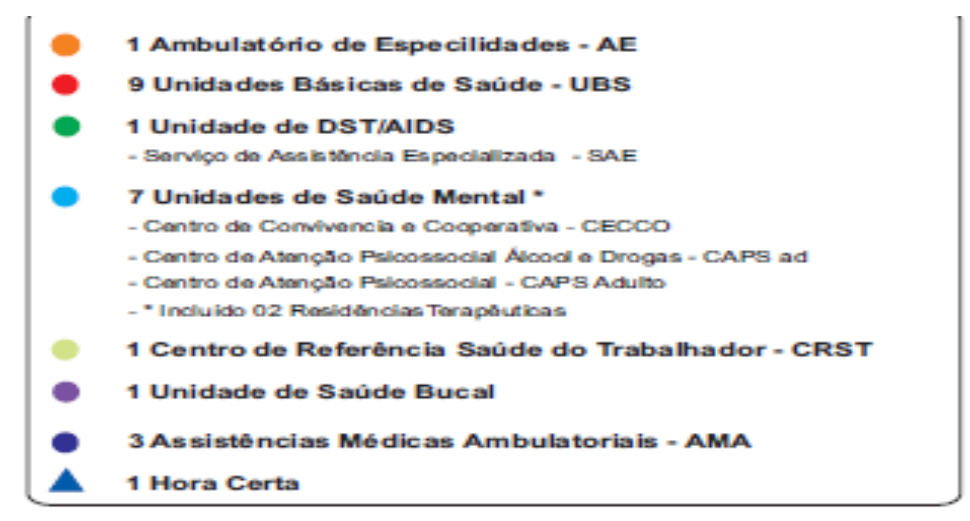

Jullho/2015

Fonte: Prefeitura de São Paulo

Disponível em: http://extranet.saude.prefeitura.sp.gov.br/areas/ceinfo/divulgacao/unid munic sub lapa.pdf

Figura 4 - Estabelecimentos e serviços de saúde da rede municipal, Coordenadoria Regional de Saúde Centro-Oeste, Município de São Paulo, julho de 2015.

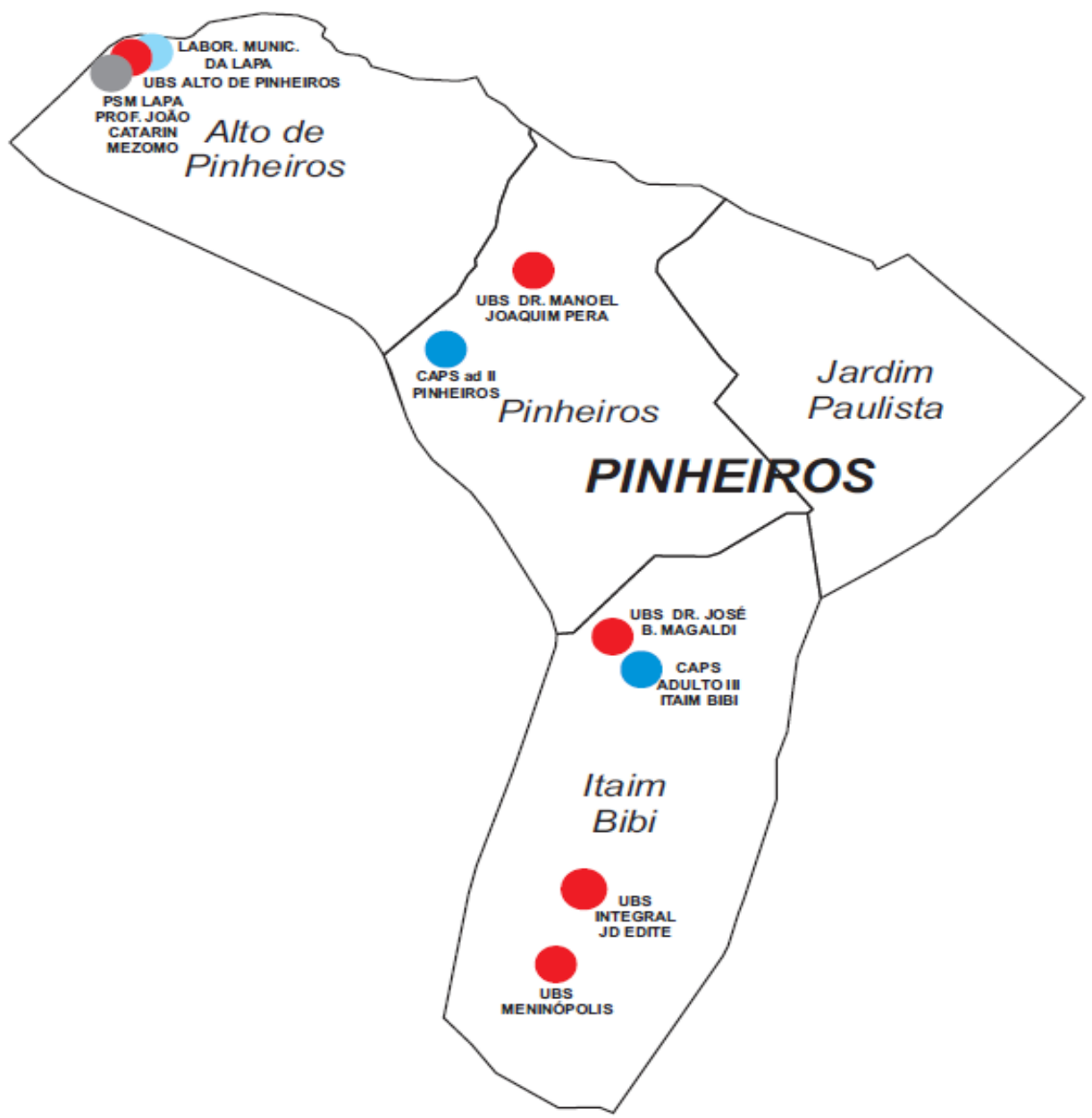




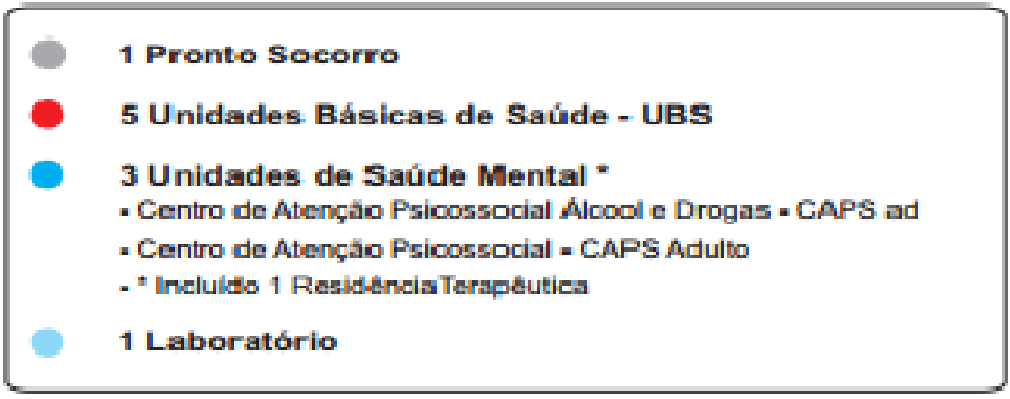

Julhol2015

Fonte: Prefeitura de São Paulo

Disponível em: http://extranet.saude.prefeitura.sp.gov.br/areas/ceinfo/divulgacao/unid munic subpinheiros.pdf

\subsection{População e amostra}

A população foi composta por enfermeiros que atuam na $A B$ na Supervisão de Saúde de Lapa/Pinheiros. Foram entrevistados profissionais de enfermagem de ambos os sexos, que não estavam em férias ou afastados do trabalho no momento da coleta de dados.

A amostra foi composta por aqueles que concordaram em participar, depois de informados sobre os objetivos da pesquisa. Uma consulta preliminar às Unidades da ESF revelou o número de equipes e enfermeiras atuantes. 
Quadro 1 - Unidades da Estratégia Saúde da Família da Supervisão Técnica de Saúde de Lapa/Pinheiros, número de equipes ESF e enfermeiras atuantes. São Paulo, 2015.

\begin{tabular}{|l|c|}
\hline UBS & $\begin{array}{l}\text { No DE EQUIPES/ } \\
\text { ENFERMEIRAS }\end{array}$ \\
\hline Jaguara & 04 \\
\hline V. N. Jaguaré & 04 \\
\hline Parque Lapa & 06 \\
\hline Vila Piauí & 03 \\
\hline Manoel Pera & 04 \\
\hline Jardim Edith & 01 \\
\hline TOTAL & $\mathbf{2 2}$ \\
\hline
\end{tabular}

Porém, ao final, a amostra resumiu-se a 12 enfermeiros, por razões vinculadas às unidades de saúde. As UBS Vila Nova Jaguaré e Manoel Pêra, em que havia oito profissionais, foram excluídos do estudo, pois não se manifestaram autorizando sua realização, mesmo após inúmeros contatos da pesquisadora, por e-mail, telefone e até pessoalmente.

Na UBS Parque da Lapa, onde havia seis enfermeiras, houve a participação apenas quatro, pois, uma vaga estava em aberto e havia uma enfermeira afastada por doença. Tampouco foi possível a participação da UBS Jardim Edith, pois a profissional estava em férias. Entretanto, na UBS Vila Jaguara, contou-se com cinco enfermeiras ao invés de quatro, pois, houve reposição de um profissional. 


\subsection{Procedimentos éticos}

O projeto de pesquisa foi submetido aos Comitês de Ética em Pesquisa (CEP) da Escola de Enfermagem da Universidade de São Paulo (EEUSP) e da Secretaria Municipal da Saúde de São Paulo, tendo sido aprovado por ambos. Após a aprovação, a pesquisadora foi pessoalmente até os serviços de saúde para apresentar a proposta de investigação e realizar a coleta de dados.

Os profissionais foram convidados a responder ao questionário de caracterização de população e às questões da entrevista semiestruturada. Ao concordarem em participar, cada um assinou o Termo de Consentimento Livre e Esclarecido - TCLE (Apêndice A), em duas vias, ficando com uma delas e entregando a outra à pesquisadora.

\subsection{Procedimentos de coleta de dados}

Ao iniciar os trâmites para realizar a coleta de dados, a Supervisão Técnica de Saúde exigiu que as UBS fossem ouvidas e que manifestassem se desejavam ou não participar do estudo, antes mesmo da apreciação do Comitê de Ética Municipal e da própria Supervisão. Não foi possível obter essa manifestação em duas das seis unidades.

Além dessa dificuldade, ao iniciar a pesquisa, em uma das UBS participantes, que segundo dados fornecidos pela Secretaria Municipal de Saúde, contava com seis profissionais enfermeiros, havia somente quatro enfermeiras e duas vagas com processo seletivo em aberto. Em outra UBS a enfermeira estava em férias no período da coleta de dados. 
Para respeitar o cronograma da pesquisa foi necessário optar pela exclusão dessas unidades e prosseguir com a coleta de dados nas outras quatro UBS que se manifestaram de forma positiva quanto à realização do estudo.

Dessa forma, a amostra foi composta por 12 participantes, que responderam ao questionário de caracterização sociodemográfica (Apêndice B) e indicaram quais instrumentos (escalas) utilizados pela equipe para identificar pacientes que necessitam de CP. Além disso, responderam à entrevista semiestruturada de acordo com seu conhecimento e convicções, relatando quais competências acreditam ser necessárias à enfermeira da $A B$ para prestar CP. 


\section{RESULTADOS}

Participaram do estudo doze enfermeiros, dos quais onze eram do sexo feminino, com idades entre 27 e 64 anos, com no mínimo 02 meses e no máximo 42 anos de formação em Enfermagem, com no mínimo uma e no máximo seis pós-graduações Lato Sensu. As mais citadas foram: Estratégia Saúde da Família, Saúde Pública e Administração Hospitalar.

O objetivo desse estudo foi e revelar as concepções sobre Cuidados Paliativos (CP) das enfermeiras da Estratégia Saúde da Família (ESF), caracterizar perfil sociodemográfico das enfermeiras da ESF Identificar os significados atribuídos pelas enfermeiras da ESF aos CP, conhecer as percepções dos enfermeiros sobre as necessidades de CP, revelar as percepções das enfermeiras sobre a formação necessária para a prestação de CP na ESF através da identificar os conhecimentos, habilidades e atitudes necessárias às enfermeiras para realizar $\mathrm{CP}$ na $\mathrm{AB}$.

Para tanto, realizamos o agrupamento dos dados de acordo com as semelhanças observadas nas respostas dos entrevistados para posterior formulação de temas.

O agrupamento dos dados nos revelou 03 temas centrais apresentados a seguir em destaque, seguidos das falas dos entrevistados que caracterizam estes temas: 


\section{TEMA 01: CONCEPÇÕES SOBRE CUIDADOS PALIATIVOS}

Ao avaliarmos os dados, fica evidente que os enfermeiros entrevistados identificam CP como cuidados prestados à pacientes em final de vida. $\mathrm{Na}$ entrevista, quando solicitado que relatassem casos de pacientes em CP atendidos, todos os enfermeiros relataram que já tiveram a oportunidade de cuidar de um paciente numa perspectiva paliativa ao longo de sua carreira. Perspectiva paliativa porque os pacientes apresentavam sinais e sintomas de doenças ameaçadoras da continuidade da vida, porém, não haviam sido encaminhados para serviços de CP diretamente. Dois dos entrevistados afirmaram ter recebido algum tipo de preparo específico para atuar em CP. Ao solicitar que relatassem o atendimento a pacientes em CP, sete mencionaram como pacientes em CP "pacientes portadores de câncer"; um entrevistado mencionou "portador de traumatismo crânio encefálico" (TCE) grave; um entrevistado mencionou "paciente portador de Alzheimer"; um entrevistado referiu "paciente portador de esclerose múltipla"; um entrevistado apontou "paciente com Doença Pulmonar Obstrutiva Crônica" (DPOC) e outro entrevistado relatou o caso de um paciente que apresentava "feridas extensas". Porém, nenhum dos entrevistados afirmou se tratarem de pacientes avaliados e indicados aos CP, uma vez que não fica claro o entendimento por parte dos entrevistados, sobre os indicadores a serem utilizados para realizar atendimento baseado em ações paliativas, ou ainda, que certifiquem 0 encaminhamento formal desse paciente aos CP. Mas todos identificaram os pacientes em CP por eles atendidos como pacientes em fase terminal ou em 
final de vida, justificando esse fato pela razão de não haver mais nada a se fazer:

“... atualmente possuo um caso na minha área de um paciente portador de neoplasia de pulmão... que era super ativo e na fase de diagnóstico já estava em fase terminal... não foi realizado quimio/rádio/intervenções cirúrgicas...”. (Enfermeira 01)

“... senhora C, 98 anos, AVC e Alzeheimer. Lembro que foi algo que a gente queria não ter passado... Porque nem sempre a gente está preparado pra ver a dificuldade do outro... a necessidade do outro e ter certeza de que não podemos fazer nada...".(Enfermeira 02)

“... senhora com 89 anos, A.R., na qual estava com câncer nos ossos, descoberto há 01 ano. Estava sendo cuidada pela filha... pelos médicos do convênio e eles (convênio), provavelmente não queriam gastar muito com casos como este...". (Enfermeira 05)

“... paciente idoso, masculino, 68 anos com CA de garganta que estava exposto e com um odor muito forte... A família tinha plena convicção de que ele 
sairia dessa condição... Não aceitavam sua condição...". (Enfermeira 07)

“... uma Sra. A.S.S. 82a, em situação de abandono familiar, com feridas de alto grau e sem possibilidade de reabilitação...". (Enfermeira 11)

“... uma paciente de 65 anos com DPOC que utilizava oxigênio,... já em fase terminal alternava momentos de lucidez e confusão, incontinência urinária e fecal, desencadeando mais atenção da equipe...”. (Enfermeira 12)

\section{Tema 02: NECESSIDADES DO PACIENTE EM CUIDADOS PALIATIVOS}

Além das questões da entrevista, tínhamos como parte do instrumento o questionário socioeconômico e nele algumas perguntas relativas à estrutura para a realização do atendimento. No questionário havia uma pergunta sobre as principais necessidades de um paciente em CP. A ideia era verificar a visão do enfermeiro sobre as principais ações a serem realizadas por eles e qual sua visão referente às necessidades em saúde de um paciente com características tão peculiares. Nas entrevistas obtivemos como resposta de quatro entrevistados que, de acordo com sua experiência, as principais necessidades são o tratamento humanizado, três participantes mencionaram o apoio à família e informação ao paciente e família sobre a condição do paciente e evolução do quadro clínico; dois fizeram referência ao conforto, ao suporte 
psicológico e emocional e à manutenção da dignidade, um mencionou o vínculo com o profissional, o comprometimento dos familiares para com os "doentes" e um entrevistado citou o alívio dor.

“... suporte psicológico/emocional, possuir um vínculo com um profissional" (Enfermeira 01)

“...Não tenho tão vasta experiência em Cuidado Paliativo... Mas acredito que Retaguarda, comprometimento dos familiares e construção de rede de apoio... (Enfermeira 02)

“... alívio da dor (conforto), apoio à família, e apoio espiritual, cuidadores, dinheiro (às vezes), informação sobre a evolução do quadro, sobre as possibilidades...”. (Enfermeira 03)

“... garantia de dignidade, que a pessoa seja tratada como ser humano, por profissionais humanizados...". (Enfermeira 04)

“... necessidade de informação...”. (Enfermeira 05)

\subsection{CRITÉRIOS PARA INDICAÇÃO DE PACIENTES AOS CUIDADOS}

\section{PALIATIVOS}

O questionário trazia também uma pergunta sobre quais seriam os critérios para indicação de um paciente aos $\mathrm{CP}$, uma vez que um dos objetivos do estudo foi identificar os instrumentos que os enfermeiros utilizam para caracterizar e indicar pacientes para CP. Obtivemos como resposta de cinco 
enfermeiros participantes do estudo, que conheciam os critérios de seleção para um paciente ser inserido em CP. Porém, ao serem questionados sobre quais seriam esses critérios, os profissionais mencionam não saber ao exatamente quais, mas citam como possíveis critérios:

- Paciente fora de possibilidade de cura;

- Prognóstico limitado;

- Dependência de cuidados continuados;

- A patologia;

- Prognóstico;

- Cura vagarosa, quase inaparente.

"Para avaliação inicial de pacientes com diagnósticos fora de possibilidades de cura, devem ser utilizados instrumentos que avaliem capacidade funcional e que podem agregar prognostico". Alguns instrumentos de avaliação inicial, validados para a utilização em CP oncológicos incluem as escalas Abaixo, segue a relação de alguns instrumentos de avaliação inicial, validados para a utilização em cuidados paliativos ontológicos.

1. Escalas de capacidade funcional: ECOG (Eastern Cooperative Oncology Group) e Karnofsky:

Permitem conhecer a capacidade do paciente para poder realizar atividades cotidianas; 


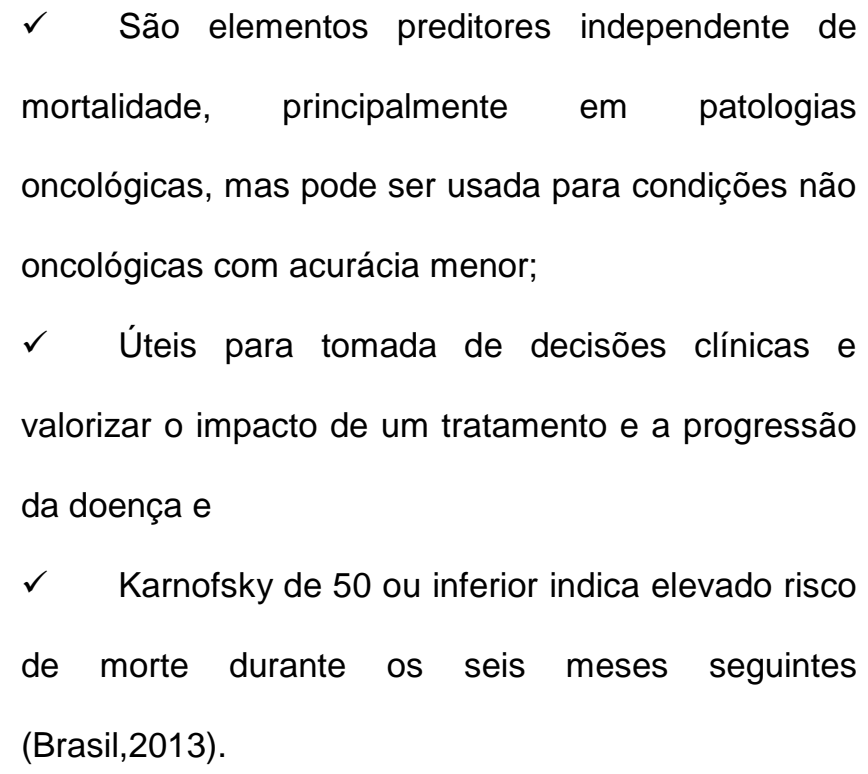

A Escala de capacidade funcional ECOG avalia de que maneira a doença afeta as habilidades de vida diária do paciente. Apresenta um escore que varia de zero a cinco pontos, e permite classificar o paciente a partir do índice 0 (totalmente ativo, capaz de continuar todo o desempenho de pré-doença, sem restrição), 1 (restritos para atividade física extenuante, porém capazes de realizar um trabalho de natureza leve ou sedentária), 2 (completamente capaz para o autocuidado, mas incapaz de realizar quaisquer atividades de trabalho; fora do leito por mais de $50 \%$ do tempo), 3 (capacidade de autocuidado limitada, restrito ao leito ou à cadeira mais de $50 \%$ do tempo de vigília), 4 (completamente limitado, não pode exercer qualquer autocuidado; restrito ao leito ou à cadeira) e 5 (morto).

A escala de resultados ou desempenho Karnofsky classifica os pacientes de acordo com o grau de falta de aptidão ou deficiências funcionais. Pode ser utilizada para comparar as diferentes terapias 
(efetividade) e para permitir prognósticos. Sua graduação vai de 0 a 100 e quanto menos a classificação na escala, pior a expectativa de recuperação das enfermidades, diminuindo assim a possibilidade de retorno às atividades normais diárias.

\section{Escalas Prognósticas:}

$\checkmark \quad$ Palliative Prognostic Score (PaP Score) estima a sobrevida, no período de 30 dias a partir da avaliação clinica e laboratorial (MALTONI, 1999; GLARE, 2003 e 2008) em pacientes com câncer em estagio final. Uma ressalva e que utiliza a estimativa clinica - Clinical Prediction of Survival (CPS) que pode ser influenciada pela experiência medica individual;

$\checkmark \quad$ Palliative Prognostic Index (PPI) - e uma escala simples que estima a sobrevida de pacientes com câncer em dias a partir do KPS e os sinais de sintomas. Diferentemente do PaP Score,não inclui o CPS, sendo o PPI mais acurado que o CPS (Brasil, 2013).

As escalas de prognostico nunca devem ser usadas isoladamente para determinar qual investimento curativo ou paliativo será aplicado. O paciente deve ser avaliado de forma multidimensional por algum período de tempo, por uma equipe preparada para avaliar pacientes com este perfil, capaz de realizar a escuta ativa das necessidades e desejos do paciente e seus familiares (Brasil, 2013). 
A escala Palliative Prognostic Score (PaP Score) usa a pontuação da KPS e mais cinco outros critérios para prever sobrevida (escore de dispneia + pontuação de Anorexia + pontuação da escala KPS + previsão clínica de sobrevivência (CPS) + pontuação total WBC ( exame de imagem que usa uma substância radioativa. É utilizado para localizar locais de infecção ou inflamação no corpo ) + Pontuação percentual de Linfócitos.

Já a Escala PPI (Índice Prognóstico Paliativo), se baseia na avaliação do estado de desempenho utilizando a Escala de Desempenho Paliativo (Karnofsky ou PPS), que verifica ingestão oral, presença ou ausência de dispneia, edema e delírio.

Correia e De Carlo (2012) afirmam que escalas de avaliação necessitam ser adaptadas culturalmente e validadas para diferentes contextos e realidades. No Brasil, serviços de assistência à saúde utilizam escalas padronizadas não adaptadas e validadas para a cultura do País, cujo uso pode compromete a definição de condutas a serem tomadas e a avaliação do cuidado a ser oferecido aos pacientes.

De maneira geral, podemos observar estudos científicos de várias especialidades em saúde utilizando as escalas para avaliar funcionalidade e não para indicar conduta para com o paciente em CP apenas.

Uma vez que observamos um processo lento de validação das escalas, percebemos a dificuldade de elegê-las como instrumento que nos possibilitem definir intervenções.

Os avanços científicos no campo dos CP exigem a sistematização e a padronização dos procedimentos de uniformização, de forma a permitir a 
mensuração de resultados, maior comunicação entre profissionais de saúde e a consolidação de suas práticas baseadas.

Se apoderar dos instrumentos que realizam esse tipo de avaliação pode proporcionar mais segurança ao profissional enfermeiro, a partir do momento que ele consegue identificar as necessidades do paciente e em conjunto com a equipe de saúde, indicar esse paciente ao $\mathrm{CP}$, que se traduz em um cuidado específico, individualizado e que pode trazer ao paciente melhor qualidade de vida e de morte e aos familiares, a sensação de que tudo o que poderia ser feito pelo seu ente querido foi realizado baseado no conhecimento técnico científico, porém, levando em consideração a humanização no cuidado e também as necessidades psicossociais do indivíduo.

\section{Tema 03: FORMAÇÃO DO ENFERMEIRO EM CP}

Partindo da perspectiva de que os entrevistados apresentassem conhecimentos sobre $\mathrm{CP}$ e fossem orientar um colega quanto à prestação de um cuidado dentro da filosofia dos $\mathrm{CP}$, os participantes foram questionados quanto à quais abordagens utilizariam com essa colega no intuito de orientá-la, dentro do que conheciam sobre CP (ou julgavam conhecer) e seis deles relataram que orientariam a recém-chegada ao serviço a realizar um atendimento humanizado, com maior possibilidade de vínculo entre profissional, paciente e família; três participantes orientariam a fornecer informações sobre redes de apoio ao paciente; dois recomendariam a oferecer conforto ao paciente e família, um orientaria sobre a necessidade de conversar 
com o paciente e família sobre o processo de morte e morrer; outro participante indicaria a necessidade de dar apoio emocional à família e ao paciente e um outro recomendaria à colega que fizesse seus atendimentos pautados na moral e na ética profissional.

“... eu acho que diria coisas simples... Não atentarse apenas às questões técnicas, mas sim ter um olhar holístico, prestando um suporte emocional à família e ao paciente e mostrar-se disposto para estabelecer um vínculo". (Enfermeira 01)

“... orientaria a procurar saber do contexto social, familiar, suas expectativas... Tanto dos familiares como a dela (paciente),... Saber sobre rede de apoio...". (Enfermeira 02)

“... Primeiramente ir com olhar abrangente e não julgar a família e a instituição em que estão vivendo. Colocar-se no lugar do familiar e do próprio paciente, pensar em como gostaria que fosse cuidado e se fosse um familiar seu... Pensar em oferecer o melhor possível dentro das limitações da família. Estar disponível a ouvir as necessidades do paciente e seus familiares... Oferecer conforto $e$ dignidade...". (Enfermeira 06)

\subsection{CONHECIMENTOS, HABILIDADES E ATITUDES}

Quando questionados a respeito dos conhecimentos necessários para cuidar do paciente em CP, nove dos entrevistados afirmaram serem 
necessários conhecimentos técnico-científicos; três participantes fizeram referência à humanização no cuidado ao paciente e à família; dois mencionaram habilidades nas relações pessoais e um participante a articulação intersetorial. Em relação às habilidades necessárias, cinco dos participantes mencionaram a escuta; três entrevistados citaram o conhecimento técnico-científico e também a cordialidade, a empatia e a disponibilidade do profissional; um dos participantes citou as habilidades específicas aprendidas na rotina do dia-a-dia profissional; um referiu o conhecimento emocional; um citou o planejamento de tratamento junto à família e um entrevistado citou gostar de estudar. Já sobre atitudes necessárias ao cuidado do paciente em CP, cinco participantes indicaram a importância do acolhimento; dois mencionaram a necessidade do respeito e da escuta; um participante afirmou que o diálogo é de suma importância; um fez referência à necessidade de identificar um membro da família com maior vínculo para que as ações do profissional sejam "de maior" eficácia e um participante citaram a cordialidade.

“... Conhecimentos científicos para prestar uma assistência que proporcione uma mínima qualidade de vida ao usuário por pior que seja o prognóstico". (Enfermeira 01)

“... Acredito que todos precisamos sempre estar buscando conhecimentos a respeito das principais questões do nosso trabalho... sempre precisamos realizar articulação intersetorial, mas acredito que 
para o início do cuidado, necessita-se de humanização". (Enfermeira 04)

Habilidades: “... Saber ouvir, não julgar, não ter preconceitos, respeitar crenças, religiosidade...". (Enfermeira 01)

“... No meu ponto de vista, emocional (conhecimento) e conhecimento do caso em si, como fazer melhor planejamento do tratamento com a família, abordagem clínica e psicológica...". (Enfermeira 05)

Atitudes: “... Primeiro... tentar dentro da escuta checar com o paciente seu desejo de aproximação familiar... Se há algum membro da família ou da rede social com vínculo, na casa dessa pessoa, mais para que ela esteja por perto para garantir conforto e tranquilidade diante dos cuidados que são prestados...”. (Enfermeira 04)

“... Olha, na minha humilde opinião, acho que precisa vínculo entende?... Amor pelo trabalho, amor pelo que faz geralmente, mas principalmente, amor pelo que estaria fazendo naquele momento... Sem isso não tem acolhimento e sem acolhimento a gente não cuida... não cuida mesmo...". (Enfermeira 10)

\subsection{CARACTERÍSTICAS ESPECÍFICAS DO ENFERMEIRO PARA ATENDIMENTO EM CP}

Quanto à necessidade de características específicas para trabalhar com pacientes em $\mathrm{CP}$, dois mencionaram a simpatia pelo perfil do paciente em $\mathrm{CP}$; 
um entrevistado citou o cuidado humanizado; um a ética; um o bom relacionamento interpessoal; um o estabelecimento de contato intersetorial e um entrevistado citou o amor ao próximo.

“... Sim, não pode realizar as ações de forma "mecânica", prestar um cuidado mais humanizado possivel, em suma, "saber ouvir"...". (Enfermeira 01)

“... Eu penso que pra qualquer área, setor... você precisa de afinidade com as características, com o que o outro espera, com as expectativas do paciente... O problema é que em $C P$, pelo menos penso assim, não se tem muita expectativa entende?" (Enfermeira 02)

“... Penso que... Ser paciente, ter empatia, estar disponível e ter equilíbrio emocional para lidar com as situações que ocorrem no dia a dia do CP...". (Enfermeira 06)

“... Sem dúvida... Acho principalmente que para trabalhar com pacientes em CP, a pessoa precisa ser mais humana, além de ser bem formada...". (Enfermeira 08)

Todos identificaram que recebem insumos, por parte da Secretaria Municipal da Saúde para atender pacientes em CP. Cabe aqui recordar que de acordo com as informações contidas no Caderno de Atenção Domiciliar do Ministério da Saúde, insumos são equipamentos, sondagens, curativos entre outros e medicamentos a serem utilizados no domicilio, distribuídos pelos serviços que compõem a rede de atenção (Brasil, 2012:4). Sendo que onze 
participantes citaram oxigênio; nove citaram apoio para discussão de casos para encaminhamento; oito a abordagem multiprofissional e sete os medicamentos.

Um dado importante a ser mencionado é que cinco dos entrevistados referiram à existência de estrutura institucional para prestar apoio às famílias de pacientes em CP; dois mencionaram receber apoio de outras secretarias, como a Secretaria Municipal de Assistência e Desenvolvimento Social (SMADS) e dois citaram a possibilidade de contar com uma estrutura para viabilizar as transferências para um hospital, se necessárias. Entretanto, apenas um referiu receber apoio da Equipe Multiprofissional de Atenção Domiciliar (EMAD) quando da necessidade de encaminhamento de pacientes em CP para algum outro tipo de atendimento de saúde; dez mencionaram apoio para encaminhamento para um setor específico do Hospital das Clínicas da Faculdade de Medicina da Universidade de São Paulo, sem, contudo saber identificar qual é esse setor. 


\section{DISCUSSÃO}

Participaram do estudo doze enfermeiros, dos quais onze eram do sexo feminino, com idades entre 27 e 64 anos, com no mínimo 02 meses e no máximo 42 anos de formação em Enfermagem, possuíam no mínimo 01 e no máximo 06 pós-graduações Lato Sensu. As mais citadas foram: Estratégia Saúde da Família, Saúde Pública e Administração Hospitalar. Apesar de prestarem cuidados de enfermagem à pacientes em $\mathrm{CP}$, relatam não haverem realizado nenhum tipo de curso para tal e tampouco se especializaram em CP.

Uma pesquisa encomendada pelo COFEN à Fundação Osvaldo Cruz (Fiocruz), intitulada "Perfil da Enfermagem no Brasil", foi realizada com 450.000 profissionais de enfermagem, dos quais $77,1 \%$ (348.227) eram técnicos e auxiliares e 22,9\% (105.438) enfermeiros; $29,6 \%$ tinham até 05 anos de formados, $28,4 \%$ de 06 a 10 anos, $12,7 \%$ de 21 a 30 anos e 5,1 mais de 30 anos. Quanto à qualificação técnico-científica da equipe de enfermagem, $21,2 \%$ possuem curso de atualização, $19,6 \%$ curso de aperfeiçoamento, 20,3\% especialização, 9,9\% graduação em enfermagem, $6,1 \%$ outra graduação, 7,6\% curso de mestrado, $4,5 \%$ curso de doutorado, $2,7 \%$ pós-doutorado e $5,4 \%$ estágios e curso no exterior.

Martins et al. (2006) afirmam ser necessário considerar que o estabelecimento do perfil do enfermeiro requer

"reconhecimento de que toda pessoa tem direito à adequada assistência de enfermagem, que 0 atendimento de enfermagem ao ser humano deve ser considerado em sua totalidade e em constante interação com o meio ambiente, que 
o enfermeiro atua em diversos campos de ação, exercendo atividades de assistência, administração, ensino, pesquisa e integração, nos níveis primário, secundário e terciário e que a constante evolução das ciências da saúde exige do enfermeiro permanente atualização e, muitas vezes, especialização, que deve ser adquirida após a formação básica".

Diante da crescente demanda por $\mathrm{CP}$, torna-se difícil contar com número suficiente de especialistas para a assistência. Tampouco essa perspectiva da atenção à saúde diz respeito apenas aos especialistas, já que a preocupação com os CP também deve envolver os profissionais de saúde generalistas, cuidadores e familiares, os quais prestam assistência primária a esses pacientes (Souza et.al., 2015).

Desse modo, o cuidado no fim da vida tem se tornado uma competência necessária para os serviços de atenção primária à saúde, principalmente pela proximidade que o cuidado na comunidade proporciona entre as equipes profissionais, os doentes e as famílias (Baliza et al., 2012).

Falamos em cuidado no fim de vida aqui, pois, de acordo com os dados de nosso estudo, os enfermeiros entrevistados identificam CP como cuidados prestados à pacientes em final de vida conforme já relatado nos resultados.

“... atualmente possuo um caso na minha área de um paciente... já estava em fase terminal..." (Enfermeira 01) 
“... ter certeza de que não podemos fazer nada...". (Enfermeira 02)

e eles (convênio), provavelmente não queriam gastar muito com casos como este...". (Enfermeira 05)

“... A família tinha plena convicção de que ele sairia dessa condição... Não aceitavam sua condição...". (Enfermeira 07)

“... uma Sra. A.S.S. 82a , sem possibilidade de reabilitação...”. (Enfermeira 11)

“... uma paciente de 65 anos com DPOC que utilizava oxigênio,... já em fase terminal...”. (Enfermeira 12)

Porém segundo a OMS (2002), os CP consistem na abordagem que promove qualidade de vida de pacientes e seus familiares diante de doenças que ameaçam a continuidade da vida, através da prevenção e alívio do sofrimento, o que requer a identificação precoce, avaliação e tratamento impecável da dor e outros problemas de natureza física, psicossocial e espiritual.

Os Cuidados Paliativos baseiam-se em conhecimentos inerentes às diversas especialidades, possibilidades de intervenção clínica e terapêutica nas diversas áreas de conhecimento da ciência médica e de conhecimentos específicos (ANCP, 2012). 
Cuidados paliativos podem ser definidos como o cuidado ativo e total prestado ao paciente cuja doença não responde mais ao tratamento curativo. Consistem em um cuidado diferenciado que visa à prevenção e alívio do sofrimento por meio da identificação precoce, da adequada avaliação e tratamento da dor e de outros sintomas físicos, psicossociais e espirituais, promovendo a qualidade de vida do paciente e de seus familiares (Baliza et.al, 2012).

Os CP apresentam-se como uma filosofia de cuidados, cujas medidas promovem a melhoria da qualidade de vida dos pacientes e seus familiares no processo de enfrentamento do fim da vida, por meio da identificação precoce, prevenção e alívio do sofrimento, avaliação e tratamento adequados dos problemas físicos, psicossociais e espirituais (Correia e De Carlo, 2012).

De acordo com Burlá (2002), terapêutica paliativa é voltada ao controle sintomático e preservação da qualidade de vida para o paciente, sem função curativa, de prolongamento ou de abreviação da sobrevida.

Os CP não se baseiam em protocolos, mas sim em princípios. Não se fala mais em terminalidade, mas em doença que ameaça a vida. Indica-se o cuidado desde o diagnóstico, expandindo o campo de atuação. Não falemos também em impossibilidade de cura, mas na possibilidade ou não de tratamento modificador da doença, desta forma afastando a ideia de "não ter mais nada a fazer". Pela primeira vez, uma abordagem inclui a espiritualidade dentre as dimensões do ser humano. A família é lembrada, portanto assistida também após a morte do paciente, no período de luto (ANCP, 2012). 
Os dados do nosso estudo evidenciam através da fala de profissionais que trabalham na $A B$ há pelo menos de 02 anos, que todos os participantes já realizaram atendimento à pacientes em $\mathrm{CP}$, porém o fazem sem preparação específica para tal. Além disso, quase que a totalidade dos entrevistados respondeu desconhecer a forma de avaliação para encaminhamento dos pacientes aos CP. Nenhum dos entrevistados soube informar se o paciente em CP por eles citados já havia sido encaminhado formalmente ao serviço de CP, apenas descreveram casos que acreditavam ser de pacientes em CP (para eles, pacientes em fase terminal) e detalharam os casos.

Os participantes identificam como critérios de avaliação para indicação de pacientes aos CP: paciente fora de possibilidade de cura; prognóstico limitado; dependência de cuidados continuados; a patologia; prognóstico e cura vagarosa, quase inaparente.

Porém não foi o que observamos. A Academia Nacional de Cuidados Paliativos (ANCP), por exemplo, em seu Guia de Cuidados Paliativos em 2012, estabelece alguns critérios de recomendação para $\mathrm{CP}$, considerando a possibilidade de indicação para aqueles pacientes que esgotaram todas as possibilidades de tratamento de manutenção ou prolongamento da vida, que apresentam sofrimento moderado a intenso e que optam por manutenção de conforto e dignidade da vida e estabelecendo então que para o cuidado prestado ao paciente fora de possibilidades de cura física seja considerado paliativo:

- Afirmação da vida e enfrentamento da morte como evento natural; 
- Aceitação da evolução natural da doença, não acelerando nem retardando a morte, e repudiando as futilidades diagnóstica e terapêutica;

- Garantia de qualidade de vida;

- Controle da dor e de outros sintomas desenvolvidos com a progressão da doença;

- Integração dos aspectos clínicos com os aspectos psicológicos, sociais e espirituais que possam influenciar a percepção e o controle dos sintomas;

- Estímulo à independência do paciente, permitindo-lhe viver de maneira ativa até a sua morte;

- Respeito à autonomia do doente com ações que levem à sua valorização como pessoa;

- Reconhecimento e aceitação, em cada doente, dos seus próprios valores e prioridades;

- Consideração de que a fase final da vida pode encerrar momentos de reconciliação e crescimento pessoal;

- Favorecimento de uma morte digna, com o mínimo de estresse possível, no local de escolha do paciente;

- Prevenção de problemas durante o luto;

- Base na diferenciação e na interdisciplinaridade.

A Associação Portuguesa de Cuidados Paliativos (APCP), em seu manual de Organização de Serviços em Cuidados Paliativos (2006), afirma que os CP devem ser oferecidos com base nas necessidades (do paciente) e não apenas no prognóstico ou no diagnóstico, pelo que podem ser introduzidos em fases mais precoces da doença, qualquer que seja ela. 
Tais características podem ser compreendidas como uma filosofia paliativista, que aponta para a necessidade premente de se viabilizar assistência especializada e humanizada, considerando-se a limitação e sofrimento físicos, o comprometimento social e emocional dos pacientes que têm o direito de receber um tratamento digno no findar da vida (SILVA, 2015).

O estudo de Baliza et al (2012), aponta que ainda restam diversos entraves à incorporação dos CP na Atenção Primária em Saúde (APS), sobretudo no que diz respeito à inabilidade dos profissionais para lidar com as famílias e à não disponibilidade de recursos tecnológicos. Este mesmo estudo, porém, destaca a capacidade desses profissionais para estabelecer vínculo com os pacientes que recebem tais cuidados, tanto por sua proximidade com essas pessoas quanto por sua qualificação e perfil diferenciado, com ênfase na inter-relação entre equipe, comunidade e família.

A APCP (2006) afirma que o doente e a família têm necessidades tanto a nível físico quanto psicológico, social e espiritual, que devem ser avaliados no momento da anamnese inicial e do exame físico geral e completo. Em complemento da avaliação inicial, deverá ser efetuada e registrada periodicamente uma avaliação das necessidades de todos os doentes e famílias, de forma a permitir dos objetivos terapêuticos e ainda a monitorização e a avaliação dos ganhos em saúde.

Os CP podem ser desenvolvidos em ambiente ambulatorial, hospitalar e no próprio domicílio do paciente. A maioria dos estudos, no entanto, enfoca o cuidado no âmbito hospitalar. Diante disso, tornam-se relevantes estudos 
destinados a compreender como essa modalidade de cuidado poderia ser realizada no domicílio pela equipe multiprofissional da APS (QUEIROZ, 2013).

Os CP na Assistência Primária à Saúde tratam de introduzir um tipo específico de atendimento que consiga ser organizado e ofertado em todos os níveis de referência, sem descontinuidade (SOUZA et al., 2015).

Vale ressaltar que os Cuidados Paliativos não se caracterizam pelo espaço físico, mas pela "filosofia de cuidados, que se concretiza no serviço prestado onde quer que o paciente se encontre" (PESSINI, 2004).

Combinato \& Martins (2012), afirmam que nesse sentido, os programas de Cuidados Paliativos podem incluir: assistência domiciliar, assistência ambulatorial, emergência, internação hospitalar, além de treinamento, pesquisa e ensino, serviços de consultoria e suporte para o luto.

Mas os dados obtidos por nosso estudo nos trazem uma realidade que nos mostra enfermeiros generalistas prestando cuidados à pacientes, realizando ações paliativas de acordo com suas possibilidades, utilizando os conhecimentos, habilidades e atitudes que adquiriram com sua prática profissional, dentro da estrutura disponível que se apresenta em um cenário que pode ser interpretado como não muito favorável à prestação desse tipo de cuidado específico devido à falta de treinamento e vivência profissional dentro desse tema especificamente.

Cuidar da pessoa fragilizada não a reduzindo a um mero corpo biológico é um grande desafio. Uma visão holística, multi, inter e transdiciplinar é 
imperiosa. O ser humano é um todo uno, um nó de relações. Ser gente é possuir corpo, é ter um psiquismo e coração, é conviver com os outros, é cultivar uma esperança e crescer na perspectiva de fé em valores humanos (Pessini e Bertachini, 2014).

Outro dado apontado por nosso estudo foi o de que os entrevistados apontam que para trabalhar com pacientes em CP a enfermeira da $A B$ deve incluir conhecimentos técnico-científicos agregados ao cuidado humanizado e que o profissional deve estar disponível e realizar o acolhimento do paciente e sua família.

Desta forma, é indispensável a formação de recursos humanos capacitados para tal prática. Contudo, a escassez de cursos e uma discreta formação relacionada aos cuidados paliativos na graduação e na pósgraduação nas diversas áreas de saúde, mesmo em oncologia (especialidade em que mais se observa o desenvolvimento dos cuidados paliativos) geram um cenário desafiador, no qual existe muito que fazer em termos de pesquisa, de ensino, de organização de serviços e de formação de recursos humanos (Baliza et al, 2012).

Um profissional é formado por uma série de experiências, pessoais e acadêmicas que o faz encarar seu trabalho de forma particular (Incontri, Santos, 2007).

Durante sua formação inicial na graduação, a enfermeira aprende que cuidar é algo inerente ao ser humano. Já o cuidado profissional de 
Enfermagem envolve o desenvolvimento de ações, atitudes e comportamentos com base em conhecimento científico, experiência e pensamento crítico, realizado para e com o paciente a fim de promover, manter ou recuperar sua saúde, quando possível, assegurando-Ihe sempre a dignidade e a totalidade humanas. Durante o exercício da profissão, as enfermeiras seguem normas e condutas objetivando salvar vidas e evitar a morte que, quando se faz presente, pode causar tristeza, perda, frustração e estresse (Oliveira, Bretas, 2007).

Em nosso referencial teórico, temos Perrenoud afirmando que os significados de competência são múltiplos e que cada elemento de um referencial de competências pode remeter a práticas antes seletivas e conservadoras ou a práticas democratizantes e renovadoras. $\mathrm{O}$ autor define competência como o conjunto formado por conhecimentos, savoir-afaire e posturas, e também ações e as atitudes necessárias ao exercício da profissão. Perrenoud (2002) considera que ser competente é ser tolerante, buscando continuamente o aperfeiçoamento da prática, sua correção, retomada para, com modéstia, ver os diferentes aspectos que devem ser considerados em função de um contexto, da história. Tomar uma decisão envolve conflitos e oposições e frequentemente os profissionais podem se sentir pouco autorizados ou pouco competentes para tomar decisões a respeito do próprio trabalho.

Temos também Chiavenato (2002), afirmando que as competências básicas se apresentam na forma de conhecimentos, habilidades, atitudes, 
interesses, traços, valor ou outra característica pessoal, são aquelas características pessoais essenciais para o desempenho da atividade e que diferenciam o desempenho das pessoas.

Podemos inferir então a necessidade de o profissional precisar para trabalhar em CP, de um conjunto de elementos, denominados: Conhecimento = Saber, o conhecer não definitivo. A busca constante pelo processo de aprender, reaprender e sempre buscar aumentar o conhecimento; Habilidade = Saber fazer, processo que usa o conhecimento para resolver problemas, que se apropria da criatividade para resolver não só problemas, mas para desenvolver e fundamentar novas ideias; Atitude = Competência = Saber fazer acontecer, define-se pela ação de obter resultados (considerados bons ou ótimos), advindos do que foi feito utilizando conhecimento e habilidade.

Sendo assim se torna através da observação dos dados contidos em nosso estudo que os enfermeiros entrevistados apresentaram dúvida ao descrever conhecimentos, habilidades e atitudes em suas respostas a esse estudo. Ao compararmos as respostas com o referencial teórico citado, percebemos a dificuldade em definir o que são competências, conhecimento, habilidades e atitudes. Através das respostas dadas pelos profissionais fica difícil diferenciar a atitude da ação de apresentação de atitude, por exemplo; assim como não é possível extrair dos dados obtidos resposta objetiva dos participantes sobre a definição do que esse profissional espera do enfermeiro da $A B$ para cuidar de um paciente em CP e sua família. 
Para Icontri \& Santos (2007), nenhum ser humano sente-se motivado a dar o melhor de si e atuar de maneira produtiva se não se sentir reconhecido, valorizado e respeitado em suas competências e habilidades.

\footnotetext{
"As ações humanizadas na atenção do profissional da saúde são indissociáveis daquilo que se poderia denominar âmbito da "sensibilidade", que, em certo sentido, é mais profundo que o âmbito do pensamento e da ação. Isso se justifica na medida em que cuidar de uma pessoa enferma tem como pressuposto existencial o fato de o cuidador ver-se ou sentir-se afastado visceralmente (afecção é da ordem do contato) por sua situação, que o próprio contato inaugura. Esse contato, por sua vez, diz respeito ao paciente em seu corpo e em sua carne vulnerável e ferida. Nesse sentido, a sensibilidade preside toda a ação do cuidador, porque está associada ao seu contato com o enfermo enquanto ele tem corpo, é seu corpo e como tal é sua carne (Pessini e Bertachini, 2014).
}

Giordani (2008) afirma que atualmente a prática da solidariedade praticamente inexiste e muitos profissionais de saúde tem-se embrutecido, o que Ihes dificulta admitir e trabalhar a própria sensibilidade no cotidiano do exercício profissional, limitando a percepção em relação ao outro. Isso leva muitas pessoas a repensar o que deverão ensinar às futuras gerações como normas de boa conduta e respeito aos semelhantes.

A humanização dos serviços de saúde em geral implica o reconhecimento do valor da pessoa humana e a compreensão do valor do 
cuidado de saúde aliado à sensibilidade diante do sofrimento humano. A humanização, a ética, o cuidado sensível, a acolhida e a hospitalidade são hoje palavras de ordem que devem se concretizar em sentimentos, atitudes e políticas de ação no frio mundo da assistência da saúde. (Pessini, Bertachini, 2014)

Porém, de acordo com os resultados obtidos, apesar do apontamento por parte dos enfermeiros, da necessidade de características específicas para se cuidar de pacientes em $\mathrm{CP}$, não fica evidente nas respostas dos participantes o entendimento da terapêutica paliativa.

Ao avaliar um dos dados coletados, verificamos que parte dos enfermeiros afirmou que, de acordo com sua experiência, as principais necessidades de um paciente em CP são o tratamento humanizado, o apoio à família e informação ao paciente e família sobre a condição do paciente e evolução do quadro clínico, o conforto, o suporte psicológico e emocional e à manutenção da dignidade, o vínculo com o profissional, o comprometimento dos familiares para com os doentes e o alívio dor. Porém nenhum deles consegue afirmar quais são os critérios para elegibilidade desses pacientes aos CP baseados em literatura por exemplo. Assim como, nenhum deles identifica precisamente quais instrumentos podem ser utilizados para eleger um paciente aos CP.

Verificando as respostas dadas pelos profissionais às questões 06 e07 deste estudo, temos respostas apontadas pelos profissionais: a necessidade de características específicas para trabalhar com pacientes em CP; a simpatia 
pelo perfil do paciente em CP; cuidado humanizado; a ética; o bom relacionamento interpessoal; estabelecimento de contato intersetorial; o amor ao próximo e como conhecimento. Como conhecimentos necessários para prestar atendimento a pacientes em CP: conhecimentos técnico-científicos; humanização no cuidado ao paciente e à família; habilidades nas relações pessoais e articulação intersetorial. Sobre as habilidades necessárias para prestar CP: escuta ativa; conhecimento técnico-científico; a cordialidade, a empatia; a disponibilidade do profissional; habilidades específicas aprendidas na rotina do dia-a-dia profissional; o conhecimento emocional; o planejamento de tratamento junto à família e gostar de estudar.

A formação dos profissionais de saúde em dor e cuidados paliativos é restrita, apesar de o cuidado fora de possibilidade de cura com o doente, estar presente em muitas situações de atendimento a pacientes com doenças crônicas. É rara a inclusão dos temas dor e cuidados paliativos nos currículos de formação de profissionais da área de saúde, embora haja algumas iniciativas sobre a proposição de um conteúdo mínimo sobre o tema (Pimenta, 2006).

A educação para lidar com a morte deveria ser um dos objetivos dos cursos, devendo ser entendida como um vasto campo de conhecimento que compreende o significado da morte, os processos de morrer, o pesar do luto e envolver intencionalidade e planejamento (Bifulco \& lochida, 2009). 
Atender adequadamente os doentes que necessitam de cuidados paliativos requer conhecimentos e habilidades próprias, algumas específicas por profissional e outras compartilhadas por todo o grupo (Pimenta, 2006).

Os participantes nos trazem respostas não específicas relativas ao assunto, não definem pontualmente o que entendem por necessidades de saúde de um paciente em CP, nem mesmo o que entendem por conhecimento, habilidades e atitudes específicas para realizar o atendimento à esse paciente para o qual apontam tantas especificidades.

Cuidados paliativos são e sempre foram inerentes ao "fazer" da enfermagem. Cuidar, educar, acolher, amparar, aliviar desconfortos, controlar sintomas e minimizar o sofrimento são ações cotidianas na vida dos profissionais (Pimenta, 2006).

A avaliação da qualidade de vida dos pacientes em CP é procedimento importante para a identificação de sua condição global, assim como para avaliar a qualidade dos serviços oferecidos (Correia \& De Carlo, 2012). 


\section{CONCLUSÃO}

Cuidar o paciente sem possibilidade de cura não é algo fácil para a família, tampouco para os profissionais de saúde, em parte por conta de sua formação. Ao ingressar na área da saúde, o estudante inicia seus estudos sobre o processo saúde-doença com ênfase nas formas de prevenção das doenças, na cura e na reabilitação. Ao longo da formação, o contato com a morte será algo episódico e ocasional. Poucas horas dos cursos de graduação na área da saúde são dedicadas a preparar os estudantes para acompanhar o processo de morte e o morrer, o que não favorece o desenvolvimento das competências necessárias para prestar os cuidados necessários aos pacientes sem possibilidade de cura....

Como desdobramento das primeiras inquietações que motivaram este estudo, no decorrer da investigação buscou-se suscitar a reflexão dos profissionais sobre as necessidades de saúde apresentadas por pacientes em CP e as condições de atendimento nos serviços de saúde.

Para tanto é necessário que o profissional enfermeiro busque atualização, realize cursos de capacitação e aprofundamento, afinal os CP são cuidados específicos e de acordo com a realidade mundial, um cuidado para população nos dias de hoje.

Os CP vieram para ocupar uma lacuna importantíssima, que precisava ser preenchida com certa urgência, proporcionando assim um cuidado mais efetivo para o paciente portador de doenças sem possibilidade de cura. 
Cuidado esse primordial para aplacar o sofrimento que nascia da falta de dignidade e impotência de pacientes e famílias diante de tamanha fúria e agressividade observadas muitas vezes por esses grupos; não por falta de empenho da equipe, mas sim em alguns casos, por falta de preparo efetivo para lidar com essas situações.

Sendo assim, verificou-se a necessidade da capacitação e orientação para manusear e utilizar instrumentos que direcionem a prática da enfermeira da $A B$ que lida com paciente em $C P$ e também do aprimoramento técnico científico direcionado especificamente para esse aspecto do processo de morte e morrer, pois, nesse momento tão delicado da vida do paciente e de seus familiares a equipe precisa estar preparada para acolher e desenvolver 0 melhor atendimento em saúde possível, pautado no conhecimento e também no cuidado humanizado. São Camilo de Lelis é autor da frase: "Mais coração nas mãos", ou seja, humanização e aprimoramento para tratar daquele que precisa de auxílio.

Talvez, a partir do momento que o ensino em saúde percorrer esse caminho e direcionamento, o cuidado com o ser humano será efetivamente individualizado e realmente "mais humano"... 


\section{REFERÊNCIAS}

1. ABCP- Associação Brasileira de Cuidados Paliativos. Fundação do Câncer - Cuidados Paliativos: Qual é o cenário dos cuidados paliativos no Brasil. [Internet]. Brasil: Fundação do câncer; [atualizado em 2015; citado em 2014 Out. 09]. Disponível em: http://www.chem.qmul.ac.uk/iubmb/.

2. ANCP - Manual de cuidados paliativos / Academia Nacional de Cuidados Paliativos. - Rio de Janeiro - Solo Editoração \& Design Gráfico, 2012. 592p.

3. ANDRADE, Maria Margarida de. Introdução à metodologia do trabalho científico: elaboração de trabalhos na graduação. São Paulo: Atlas, 2003, 174p.

4. APCP- Associação Portuguesa de Cuidados Paliativos. Critérios de Qualidade para Unidades de Cuidados Paliativos (2006). [Internet]. Portugal; [atualizado em 2015]. Disponível em: http://www.apcp.com.pt/diretivas-recomendacoes-apcp/criterios-dequalidade-para-unidades-de-cuidados-paliativos.html

5. APCP- Associação Portuguesa de Cuidados Paliativos. Recomendações para Organização de Serviços de Cuidados Paliativos (2006). [Internet]. Portugal; [atualizado em 2015]. Disponível em: http://www.apcp.com.pt/uploads/Recomendacoes Organizacao de Servicos.pdf

6. BALIZA MF, Bousso RS, Spineli VMCD, Silva L, Poles K. Cuidados paliativos no domicílio: percepção de enfermeiras da Estratégia Saúde da Família. Revista Acta Paulista Enfermagem, São Paulo. 2012; 25 (Número Especial 2):13-8.

7. BIFULCO, Vera Anita; IOCHIDA, Lúcia Christina. A formação na graduação dos profissionais de saúde e a educação para o cuidado 
de pacientes fora de recursos terapêuticos de cura. Revista Brasileira de Educação Médica, São Paulo. 2009; 33(1):92 - 100.

8. BOUSSO RS; Poles K, Rossato LM. Desenvolvimento de conceitos: novas direções para a pesquisa em tanatologia e enfermagem. Rev. esc. enferm. USP [online]. 2009, vol.43.

9. BRASIL (1). Lei no $\mathbf{8 . 0 8 0}$, de 19 de setembro de 1990. Dispõe sobre as condições para a promoção, proteção e recuperação da saúde, da organização e funcionamento dos serviços correspondentes e dá outras providências (Lei Orgânica da Saúde). Diário Oficial da União, Brasília, DF, 1990.

10.BRASIL (2). Ministério da Saúde. Secretaria de Atenção à Saúde. [internet]. Brasília; 2006 [citado 2013 set. 16]. Disponível em: http://www.saude.sp.gov.br/ses/perfil/gestor/atencao-basica/

11.BRASIL (3). Ministério da Saúde/Secretaria de vigilância em Saúde. Departamento de análise de situação de Saúde. Plano de ações estratégicas para o enfrentamento das doenças crônicas não transmissíveis (DCNT) no Brasil 2011 - 2012. Brasília: Ministério da Saúde, 2011. 160p.: Il. - Série B. Textos Básicos de Saúde)

12. BRASIL (4). Ministério da Saúde. Secretaria de Atenção à Saúde. Departamento de Atenção Básica. Caderno de atenção domiciliar / Ministério da Saúde, Secretaria de Atenção à Saúde, Departamento de Atenção Básica. - Brasília: Ministério da Saúde, 2012. $1 \mathrm{vl.}$

13. BRASIL (5). Ministério da Saúde. Secretaria de Atenção à Saúde. Departamento de Atenção Básica. Caderno de atenção domiciliar / Ministério da Saúde, Secretaria de Atenção à Saúde, Departamento de Atenção Básica. - Brasília: Ministério da Saúde, 2013. 2 vl. 
14.BRASIL (6). Ministério da Saúde. Instituto Nacional do Câncer José Alencar Gomes da Silva (INCA). Estimativa 2012: incidência de câncer no Brasil. Rio de Janeiro: MS; 2011.

15. BRETAS JRS, OLIVEIRA JR, Yamaguti L. Reflexões de estudantes de enfermagem sobre morte e o morrer. Rev. esc. enferm. USP, São Paulo, v. 40, n. 4, dez. 2006.

16. BURLÁ, Claudia. Controle de sintomas do câncer avançado em adulto: normas e recomendações do INCA/MS. Revista Brasileira de Cancerologia 2002;v.48(2),p.191-211.

17. CHIAVENATO I. Teoria Geral da administração. $6^{\circ}$ Edição, vol.2. Rio de Janeiro: Elsevier, 2002.

18. COMBINATO, Denise Stefanoni; MARTINS, Sueli Terezinha Ferreira. (Em defesa dos) Cuidados Paliativos na Atenção Primária à Saúde. O Mundo da Saúde. São Paulo, 2012; 36 [3]: 433-441.

19. CORREIA, Fernanda Ribeiro. Tradução, adaptação cultural e validação inicial no Brasil da Palliative Outcome Scale (POS). Ribeirão Preto, 2012.

20. CORREIA, Fernanda Ribeiro; De Carlo, Marysia Mara Rodrigues do Prado. Avaliação da qualidade de vida no contexto dos cuidados paliativos: revisão integrativa de literatura. Rev. Latino-Am. Enfermagem [online]. 2012, vol.20(2), mar-abr.

21. CREMESP - Conselho Regional de Medicina do Estado de São Paulo. Cuidado Paliativo. Coordenação Institucional de Reinaldo Ayer de Oliveira. São Paulo: Conselho Regional de Medicina do Estado de São Paulo, 2008. 
22. FLORIANI, Ciro Augusto; SCHRAMM, Fermin Roland. Casas para os que morrem: a história do desenvolvimento dos hospices modernos. História, Ciências, Saúde - Manguinhos - v.17, supl.1, jul. 2010, p.165-180.

23. GIL AC. Como elaborar projetos de pesquisa. 4. ed. São Paulo: Atlas, 2007, 176p.

24. GIORDANI, Annecy Tojeiro. Humanização da saúde e do cuidado. São Caetano do Sul, SP: Difusão Editora, 2008. 191p.

25. HERMES HR, LAMARCA ICA. Cuidados paliativos: uma abordagem a partir das categorias profissionais de saúde. Ciênc. saúde coletiva [online]. 2013, vol.18, n.9.

26. INCONTRI D, Santos FS. (org.). A arte de morrer: visões plurais. Bragança Paulista, SP. Editora Comenius, 2007.

27. IOELC - International Observatory on End of Life Care. Global Development. United Kingdom: IOELC, 2008. Disponivel em: <www.eolc-observatory.net>. Acesso em: out. 2008.

28. LE BOTERF, G. Compétense et navigation professionelle. Paris: Éditions d'Organisations, 2000.

29. LEONELLO, Valéria Marli; OLIVEIRA, Maria Amélia de Campos. Construindo competências para ação educativa da enfermeira na atenção básica. Rev. esc. enferm. USP, São Paulo, v. 41, n. spe, p. 847-852, Dec. 2007 . Available from <http://www.scielo.br/scielo.php?script=sci_arttext\&pid=S008062342007000500019\&Ing=en\&nrm=iso>. access on 13 Jun. 2016. http://dx.doi.org/10.1590/S0080-62342007000500019

30. MACEDO, L de; PETTY, A.L.S.; PASSOS, N.C.. Aprender com jogos e situações problema. Porto Alegre: Artmed, 2000. 
31.MARCHI, Joisy Aparecida; PAULA, Cristiane Cardoso de; GIRARDONPERLINI, Nara Marilene Oliveira and SALES, Catarina Aparecida. SIGNIFICADO DE SER-CUIDADOR DE FAMILIAR COM CÂNCER E DEPENDENTE: CONTRIBUIÇÕES PARA A PALIAÇÃO. Texto contexto - enferm. [online]. 2016, vol.25, n.1 [cited 2016-05-02], e0760014. Available from: <http://www.scielo.br/scielo.php?script=sci_arttext\&pid=S010407072016000100311\&Ing=en\&nrm=iso>. Epub Mar 22, 2016. ISSN 1980-265X. http://dx.doi.org/10.1590/0104-07072016007600014.

32. MARQUES, CMS, EGRY, EY. As competências profissionais em saúde e as políticas ministeriais. Rev Esc. Enferm USP. 2011; 45(1): 187-93.

33. MARTINS, Christiane et al. Perfil do enfermeiro e necessidades de desenvolvimento de competência profissional. Texto contexto enferm., Florianópolis, v. 15, n. 3, p. 472-478, set. 2006 . Disponível em $\quad<h t t p: / / w w w . s c i e l o . b r / s c i e l o . p h p ? s c r i p t=s c i \_a r t t e x t \& p i d=S 0104-$ 07072006000300012\&lng=pt\&nrm=iso >. acessos em 13 Jun. 2015. http://dx.doi.org/10.1590/S0104-07072006000300012.

34. MENDES, E. C.; VASCONCELLOS, L. C. F.. Cuidados paliativos no câncer e os princípios doutrinários do SUS. Saúde Debate | Rio de Janeiro, V. 39, N. 106, P. 881-892, Jul-Set 2015.

35. MITCHELL G. Primary palliative care: facing twin challenges. Aust Fam Physician. [Internet]. 2011 [acesso 28 abr 2016]; 40 (7):517-8. Disponível: http://www.racgp.org.au/download/documents/ AFP/2011/July/201107mitchell.pdf 
36. Pastrana T, De Lima L, Pons JJ, Centeno C (2013). Atlas de Cuidados Paliativos de Latinoamérica. Edición cartográfica 2013. Houston: IAHPC Press

37.PAZ, Cassia Regina de Paula. Cuidados paliativos na atenção primária: Novos desafios. São Paulo: 2013. 103p.

38. PEREIRA, Esdras Edgar Batista; SANTOS, Nadia Barreto dos; SARGES, Edilene do Socorro Nascimento Falcão. Avaliação da capacidade funcional do paciente oncogeriátrico hospitalizado. Rev Pan-Amaz Saúde, Ananindeua, v. 5, n. 4, dez. 2014.

39. PERRENOUD, Philippe. Construir as competências desde a escola. Porto Alegre: Artmed, 1999. 90p.

40. PERRENOUD, Philippe. Dez novas competências para ensinar. Porto Alegre: Atmed, 2000. 192p.

41.PERRENOUD, Philippe et al. Formando professores profissionais: Quais estratégis? Quais Competências. Porto Alegre: Atmed, 2001. 232p.

42. PERRENOUD, Philippe et al. As competências para ensinar no século XXI: a formação de professores e o desafio da avaliação. Porto Alegre: Atmed, 2002. 176p.

43.PESSINI, L. Cuidados paliativos: alguns aspectos conceituais, biográficos e éticos. Prática hospitalar 2005; (41): 107-12

44.PESSINI, L et.all. Bioética, cuidado e humanização: humanização dos cuidados de saúde e tributos de gratidão. São Paulo: Centro Universitário São Camilo, Edições Loyola - IBCC: Centro de Estudos, 2014. Vol.III. 280p. 
45. PESSINI L. A filosofia dos cuidados paliativos: uma resposta diante da obstinação terapêutica. In: Pessini L, Bertachini L, organizadores. Humanização e cuidados paliativos. São Paulo: Loyola; 2004. p. 181-208.

46. PIMENTA, Cibele Andrucioli de Mattos. Dor e cuidados paliativos: enfermagem, medicina e psicologia. Baruei, SP: Manole, 2006. 498p.

47.POLIT, Denise F.. Fundamentos de pesquisa em enfermagem: avaliação de evidências para a prática da enfermagem. $7^{\circ}$ Edição Porto Alegre: Artmed, 2011, 669p.

48. QUEIROZ AHAB, Pontes RJS, Souza AMA, Rodrigues TB. Percepção de familiares e profissionais de saúde sobre os cuidados no final da vida no âmbito da atenção primária à saúde. Ciênc Saúde Coletiva. [Internet]. 2013 [acesso 29 abr 2016];18(9):2615-23. Disponível: http://dx.doi.org/10.1590/S1413-81232013000900016

49.SANTOS, Franklin Santana. Cuidados Paliativos: diretrizes, humanização e alívio de sintomas. São Paulo: Editora Atheneu, 2011, $654 p$.

50.SAMPIERI, Roberto Hernandez. Metodologia de Pesquisa. $3^{\circ}$ Edição São Paulo: McGraw-Hill, 2006, 583p.

51.SILVA, Giselle de Fátima. Cuidados Paliativos e Subjetividade: ações Educativas sobre a vida e o morrer / Giselle de Fátima Silva; orientador Fernando Luis González Rey. -- Brasília, 2015. 234 p.

52.SILVA L, Poles K, Baliza MF, Silva MCLSR, Santos MR, Bousso RS. Cuidar de famílias de idosos em final de vida na Estratégia Saúde da Família. Rev. Latino-Am. Enfermagem [online]. 2013, vol.21, n.1. 
53. TRIVIÑOS, A. N. S. Introdução à pesquisa em ciências sociais: a pesquisa qualitativa em educação. São Paulo: Atlas, 1987, 175p.

54.WHO, World Health Organization. National Cancer Control Programmes: policies and managerial guidelines. Geneva: WHO, 2002. 


\section{APÊNDICE A \\ TERMO DE CONSENTIMENTO LIVRE E ESCLARECIDO}

Cara (o) colega,

Meu nome é Luciene Jacinto de Souza, RG 17.944.378-1, sou enfermeira e estudante matriculada no Programa de Pós-graduação em Enfermagem da Escola de Enfermagem da USP (EEUSP), nível de mestrado. Estou desenvolvendo um estudo intitulado Cuidados Paliativos na Atenção Básica: competências necessárias à enfermeira da Estratégia Saúde da Família, cujos objetivos são:

- Caracterizar as competências necessárias às enfermeiras para realizar CP na Atenção Básica;

- Caracterizar o perfil das enfermeiras que prestam cuidados paliativos na Atenção Básica e

- Verificar que tipo de preparo que a enfermeira da Atenção Básica recebe para lidar com os pacientes em cuidados paliativos.

Sua participação é muito importante para o alcance dos objetivos desta pesquisa, Assim, convido-a (o) a participar voluntariamente. Para isso, será necessário responder um questionário de caracterização sociodemográfica, indicar os pacientes atendidos pela Unidade em cuidados paliativos e responder algumas questões sobre a atenção dispensada a esses pacientes.

Asseguro-lhe que seus dados serão mantidos em sigilo. Você terá a liberdade de desistir de participar da pesquisa sem que haja qualquer prejuízo ou sanção. Os resultados obtidos poderão ser utilizados para apresentação em 
eventos científicos e publicações em periódicos, mas seu anonimato será mantido.

Se desejar, você poderá ter acesso aos resultados deste estudo, entrando em contato diretamente com a pesquisadora, por meio do e-mail luciene.jacinto@usp.br ou telefone (11) 98126-7339.

Caso haja qualquer dúvida relacionada à ética na pesquisa, você poderá entrar em contato com o Comitê de Ética em Pesquisa da EEUSP 3061-7548 ou diretamente com a orientadora, Prof $^{\underline{a}} \mathrm{Dr}^{\mathrm{a}}$ Maria Amélia de Campos Oliveira, do Departamento de Enfermagem em Saúde Coletiva da USP, pelo telefone $3061-7652$

Tendo sido esclarecido sobre os objetivos do estudo e sobre o caráter voluntário de minha participação, consinto em participar desta investigação.

$$
\text { São Paulo, }
$$
de 2015.

Assinatura do entrevistado (a):

Assinatura da pesquisadora: 


\section{APÊNDICE B - Questionário para caracterização sociodemográfica e profissional dos participantes}

1. Nome:

2. Data de nascimento:

3. Sexo: ( ) Feminino ( ) Masculino

4. Em que ano você se formou?

5. Onde?

6. Possui alguma especialização? ( ) Não ( ) Sim Em que área?

7. Cursou o Mestrado? ( ) Não ( ) Sim. Em que área?

8. Cursou Doutorado? ( ) Não ( ) Sim. Qual?

9. Você fez algum curso sobre a morte e o morrer? ( ) Não ( ) Sim Qual?

10. Há quanto tempo você trabalha na Atenção Básica? Desde (mês/ano)

11. Durante seu período de treinamento (ou experiência) na $A B$, você recebeu algum preparo para lidar com o processo de morte e morrer? ( ) Não ( ) Sim. Qual?

12. Realiza atendimento à pacientes sem possibilidade de cura?( ) Não ( ) Sim

13. Você já cuidou de algum paciente indicado para Cuidados Paliativos (CP)?

( ) Não ( ) Sim 
14. Sabe conhece os critérios utilizados para indicar um paciente para CP?

( ) Não ( ) Sim.

Quais?

16. Você conhece algum instrumento utilizado para definir o paciente elegível para CP? ( ) Não ( ) Sim.

Qual?

17. Você utiliza algum deles na AB? ( ) Não ( ) Sim. Qual? 


\section{APÊNDICE C: Roteiro para entrevista}

1. Gostaria que você relatasse o caso de um paciente em CP atendido por você na $A B$.

2. Imagine que você vá receber uma colega enfermeira que nunca prestou CP na $A B$ e que tem um paciente nessas condições. O que você lhe diria?

3. Que conhecimentos você acredita que ela deveria ter?

4. Que habilidades seriam necessárias?

5. Que atitudes ela deveria ter para com o paciente em CP e sua família?

6. Você acredita que para trabalhar nos CP o profissional precisa ter alguma característica específica? Quais?

7. De acordo com sua experiência, quais são as principais necessidades de um paciente em CP? 